\title{
Margin Trading and Comovement During Crises*
}

\author{
Bige Kahraman
}

\author{
Heather Tookes
}

August 2019

\begin{abstract}
We exploit threshold rules governing margin trading eligibility in India to identify a causal link between margin trading and increased comovement during crises. Margin trading explains more than one quarter of the increase return comovement that we observe during crises. To understand the mechanisms driving this result, we evaluate the relative importance of stock connections through common brokers (who provide margin financing) versus common margin traders. We find that common brokers are most important. Margin-eligible stocks that are more connected through common brokers experience larger crisis-period increases in pairwise return comovement, especially when those brokers' clients have experienced recent portfolio losses, when their clients have outstanding margin loans in more volatile stocks, and when the brokers are large. These findings are consistent with Brunnermeier and Petersen (2009), in which initial shocks propagate due to the tightening of margin constraints imposed by financial intermediaries.
\end{abstract}

\footnotetext{
* We would like to thank seminar participants at Cornell, the Federal Reserve Bank of New York, the Federal Reserve Board, Georgia State, Georgia Tech, University of Miami, and the University of Colorado. We would also like to thank discussants and participants at the 2017 University of Oregon Summer Finance Conference, 2016 HEC-McGill Winter Finance Conference, 2017 European Finance Association, and the 5th Luxembourg Asset Management Summit for their comments on an earlier version of this paper. We are grateful to Nirmal Mohanty, Ravi Narain, R. Sundararaman, C. N. Upadhyay, and staff at the NSE for providing us with institutional information. Minhua Wan provided excellent research assistance. A portion of this project received financial support from the 2013- 2014 NSE - NYU Stern Initiative on the Study of Indian Capital Markets. The views expressed in this paper are those of the authors and do not necessarily represent those of NSE or NYU. This paper circulated previously under the title "Systematic Liquidity and Leverage." Author contact information: Bige Kahraman, Said Business School, Park End Street, Oxford OX1 1HP, UK, bige.kahraman@sbs.ox.ac.uk. Heather Tookes, Yale School of Management, PO Box 208200, New Haven, CT 06520, heather.tookes@yale.edu.
}

Keywords: Margin Trading, Comovement, Crisis, Funding Constraints, Leverage, Regression Discontinuity Design 


\section{Introduction}

Does margin trading magnify the return comovement that we observe during crisis periods? Even without changes in common fundamentals, Brunnermeier and Petersen (2009) argue that shocks can be amplified and propagated throughout a financial system through the tightening of margin constraints imposed by financial intermediaries and the deleveraging of traders who rely on borrowing. Initial losses spill over to other assets and drive return comovement that is unrelated to fundamentals (“excess comovement"). The idea that price declines are more correlated during crisis is alarming because these are precisely the times during which traders' portfolios are most vulnerable. Moreover, the ubiquity of margin trading systems in global financial markets means that it is important to understand the reasons why margin trading can drive crisis-period excess comovement. In this paper, we exploit the threshold rules governing margin trading eligibility in India to identify a causal relationship between margin trading and the extent to which a stock's returns covary with the returns of other stocks. We find that margin trading explains more than one quarter of the crisis-period increases in return comovement.

Brunnermeier and Oehmke (2013) lay out two ways in which an initial, potentially modest, shock to capital can cause spillovers in a system in which traders use leverage. In a "loss spiral", the initial shock to the value of one asset reduces traders' net worth, making leverage constraints bind and causing the sales of many assets in investors' portfolios, which in turn lead to further declines in asset values and further sales. In a "margin spiral," the initial loss and resulting increase in volatility causes intermediaries to tighten margin requirements, causing leverage constraints to bind. Both of these can happen simultaneously. To understand why margin trading exacerbates return comovement during 
crises, we exploit unique trader-level data, in which we observe the daily outstanding margin positions of each margin trader in the market as well an identifier for the broker providing the margin loan. Specifically, we evaluate the relative importance of connections through common brokers versus common margin traders in propagating negative shocks. Overall, we find that the broker channel is most important.

The idea that margin trading can cause heightened comovement during crises has robust support in the theoretical literature; however, there are serious empirical challenges to conducting clean tests of this hypothesis. ${ }^{1}$ To assess the extent to which margin trading (a form of funding due to leverage) matters, one would need to observe variation in trader leverage due to margin loans. More importantly, one would also have to separate the effects of crisis-period deleveraging from confounding effects arising from market-wide changes in fundamentals. Distinguishing the comovement due to frictions versus fundamentals is critical to understanding the potential amplification mechanisms. The margin trading regulations in India allow us to overcome these identification challenges.

In India, only some exchange-traded stocks are eligible for margin trading. Importantly, eligibility is based on a well-defined cutoff. The discreteness of the margin trading rules provides a discontinuity (see Lee and Lemieux, 2010) in the ability of traders to use leverage, and therefore provides us an opportunity to perform a regression discontinuity design (RDD) to identify the causal effect of margin trading on return comovement. Moreover, for a 4-year subsample period, we have a novel dataset in which we observe all outstanding margin loans at the trader-stock-day level. These

\footnotetext{
${ }^{1}$ Examples in this theoretical literature include Brunnermeier and Pederson (2009), Gromb and Vayanos (2002), Morris and Shin (2004), Weill (2007), Kyle and Xiong (2001), and Gromb and Vayanos (2009).
} 
data also include an identifier for the broker providing the margin financing and allow us a unique opportunity to examine the loss spiral and margin spiral mechanisms that could each drive causal links between margin trading and crisis-period comovement.

Like other stock markets around the world, Indian equity markets are characterized by return comovement that tends to increase during downturns. Figure 1, Panel A shows that comovement increases sharply when there are large drops in market returns. Figure 1, Panel B shows the same time series of comovement, but for the subsample of stocks that are close to the margin trading eligibility threshold. The patterns in Figure 1, Panel B are revealing. During almost all market downturns, the return comovement in margin eligible stocks is much higher than that of margin ineligible stocks. During other periods, there are small (if any) differences between the two groups. The figures provide simple, yet striking, evidence consistent with the hypothesis that funding constraints in bad times drive comovement.

In the formal regression analysis, we use regression discontinuity design (RDD) to identify the causal effect of margin trading. Consistent with downward price pressure due to the deleveraging of traders who rely on borrowing (e.g., Gromb and Vayanos, 2002; Brunnermeier and Pedersen 2009), we find that margin trading amplifies return comovement during crisis periods. The economic effect is substantial: during crises, there is an additional $27 \%$ increase in return comovement due to margin trading. Importantly, this effect is solely driven by crisis periods. During non-crisis periods and even during market rallies, margin trading has no effect on comovement. Our results are robust to a battery of RDD robustness tests (e.g., parametric regressions with polynomials; placebo tests around false eligibility cutoffs). We also show that the main effect is not driven by shorting eligibility, derivatives 
trading, index membership or differences in ownership structure (such as institutional and foreign ownership). Thus, the leverage channel is distinct from prior findings in the literature.

Given the robust evidence of a causal role for margin trading, we turn to the analysis of the mechanisms driving the result. If the causal impact of margin eligibility on comovement is due to frictions related to binding collateral constraints and deleveraging, we would expect the increases in comovement during crises to be strongest between the stocks in which traders tend to use leverage. In other words, we would expect pairwise correlations in stocks' returns to be higher within the set of margin-eligible stocks. This is precisely what we find. Moreover, when we measure the pairwise correlation in daily outstanding margin positions of margin-eligible stocks, we find that stocks with higher margin trading correlations also exhibit higher pairwise return comovement. These findings are consistent with margin traders, as a group, simultaneously unwinding their positions in multiple stocks when the value of their collateral falls.

Our data allow us to zoom in further to understand potential cross-stock linkages. Using the unique trader and broker identification numbers, we identify the margin trader and the broker linkages across stocks. Using this information, we examine the importance of common traders and common brokers on the heightened return comovement during crises. Both the broker and trader channels are of interest. At the trader level, leverage-induced funding constraints might force a trader to liquidate positions in multiple stocks in her portfolio. At the broker level, a negative shock to the market might make the broker less willing to provide capital to its customers. We find that margin-eligible stocks that are more connected through brokers experience much larger increases in pairwise comovement 
in returns during severe market downturns. We find that broker effects subsume any direct trader effects and are, at least in part, driven by recent losses to brokers' margin loan portfolios.

Finally, we perform cross-sectional tests to shed light on the relationship between broker characteristics and excess comovement during crisis periods. We consider a number of variables, such as the broker size, client and stock concentration, and the characteristics of the stocks that the broker has in its margin loan portfolio. We find that large brokers and brokers with margin loan portfolios that have higher volatility are the most important determinants of heightened return comovement during crisis periods. These findings provide direct evidence supporting the mechanism in Brunnermeier and Petersen (2009).

The fact that return comovement increases during crises is widely documented; however, its underlying causes are not well-understood..$^{2}$ In this paper, we focus on a potential role for margin trading. Our paper adds to this literature by providing causal evidence on the impact of margin trading on excess return comovement that we observe during crisis periods.

In related work, Chung and Kang (2016) examine the role of prime brokers in generating correlations in hedge fund returns. They find limited evidence for contagion through funding constraints mechanism. Unlike Chung and Kang (2016), who do not observe hedge funds' margin debt with the broker, we observe this information for each margin trader in the market. Therefore, for each stock, we are able to measure the extent of linkages with all the other stocks through common brokers and common margin traders. Our analysis on assessing the relative effects of common broker

\footnotetext{
2 The empirical evidence is not conclusive. Examples in this literature include Bekaert, Harvey, and $\mathrm{Ng}$ (2005) and Jotikasthira, Lundblad, and Ramadorai (2012), who document heightened return comovement during crisis periods in international markets. Boyson, Stahel, and Stulz (2010) and Billio, Getmansky, Lo, and Pelizzon (2012) provide evidence consistent with contagion among hedge funds.
} 
and common trader linkages on stocks' return patterns is new and it contributes to debates on whether funding constraints arising on the borrower's or the lender's side are more important (e.g., see Brunnermeier and Oehmke, 2013 for a review). Our results show that policies which aim to recapitalize or subsidize lenders (instead of borrowers) can be more effective in mitigating losses during crises.

In very recent work, Bian, He, Shue, Zhou (2018) and Bian, Da, Lou, and Zhou (2018) examine margin investors in China during May through July 2015 (a period of market turmoil). Both papers document significant deleveraging during stressed market conditions. The Bian, Da, Lou, and Zhou (2018) paper is closest to our work in that the authors link margin trading to return spillovers. The authors report that a stock's returns can be forecasted by the returns of stocks with which it shares common margin investors. These findings are complementary to ours; however, there are some important differences to highlight. The first is our identification strategy, made possible by the Indian regulatory environment. Different from our paper, Bian, Da, Lou, and Zhou (2018) do not exploit a (quasi) natural experiment to make causal statements. Second, we aim to understand the relative impact of stock connections via common margin traders versus common brokers. We are able to draw comparisons because we observe margin position data for the entire market. The data in Bian, Da, Lou, and Zhou (2018) are from a single broker and online platform in China, therefore they are not able to examine variation in broker connections. Instead they use very detailed trader portfolio data to compare margin traders to those that do not use leverage.

Our paper is also related to recent work by Kahraman and Tookes (2017), who use the same sample of stocks that we use in this paper, but they focus on whether margin trading impacts stock- 
level liquidity. They report that margin trading improves stock liquidity during normal times, but that the effect reverses during crises. In this paper, we are interested in the market-level question of whether margin trading is a propagation mechanism leading to excess comovement in stock returns during crisis periods. This economic question is distinct from that in Kahraman and Tookes (2017). Importantly, unlike Kahraman and Tookes (2017), we introduce new data at the margin trader and broker level, which helps us to uncover the mechanisms through which negative shocks propagate and cause heightened comovement during crises. Our finding that the economic effect of common brokers is larger than that of common traders is, to the best of our knowledge, new to the literature and it contributes to ongoing policy debates.

\section{Margin trading in India}

Margin trading allows traders to borrow in order to purchase shares. In India, the margin trading system is regulated by the Securities and Exchange Board of India (SEBI). The current system, in which margin trading is allowed in stocks that meet certain eligibility requirements, has been in place since April $2004 .{ }^{3}$ Under current SEBI guidelines, two criteria must be met for a stock to be eligible. The first is that the stock must have traded on at least $80 \%$ of the trading days over the past 18 months. The second requirement provides the identification that we need for the empirical analysis. The stock's average impact cost, defined as the absolute value of the percentage change in price from the bid-offer midpoint that would be caused by an order size of 100,000 rupees (approximately $\$ 2,000$

\footnotetext{
${ }^{3}$ Prior to the current system, the primary borrowing mechanism for traders in India was a system called Badla. Under Badla, trade settlements were rolled from one period to another. The system was eventually banned because it lacked key risk management standards, such as maintenance margins.
} 
during our sample period), must be less than or equal to $1 \%$. The impact cost used to determine eligibility is based on the average of estimated impact costs over the past six months. These are calculated from four random order book snapshots per day.

Stocks that meet the impact cost and trading frequency requirements are categorized as Group 1 stocks and are eligible for margin trading. Stocks that fail to meet the impact cost requirement, but meet the trading frequency requirement, are categorized as Group 2 stocks. All remaining stocks are classified into Group 3. Group 2 and Group 3 stocks are ineligible for margin trading. ${ }^{4}$ Impact costs and the resulting group assignments are calculated on the $15^{\text {th }}$ day of each month. The new groups are announced and become effective on the $1^{\text {st }}$ day of the subsequent month. For example, when determining eligibility for the month of December, regulators use data from May 15 through November 15 to determine each stock's eligibility. The resulting group assignments are announced on December 1 and are effective for the entire month of December. For stocks that meet the $80 \%$ trading frequency requirement, the probability of eligibility shifts unequivocally from 0 to 1 at the $1 \%$ impact cost cutoff. This feature allows us to employ a sharp regression discontinuity design.

Margin traders can set up margin trading facilities with only one broker at a time, and brokers must report outstanding margin loans of each client in each stock to the regulators on a daily basis. The daily client-level data were provided to us by the National Stock Exchange of India for the years 2007 through 2010. They cover the entire market and allow us to analyze trader and broker-driven channels that might drive excess comovement. Note that brokers can also borrow to provide margin

\footnotetext{
${ }^{4}$ When a stock moves from Group 1 to Group 2 or 3, no new margin trades are allowed as the effective date. However, investors who already have outstanding margin positions can take time to unwind them.
} 
financing. Because brokers also set the margin requirements, constraints that they face are expected to impact stock comovement.

There are alternative ways that traders can obtain leverage in India outside of the formal margin trading system, but these channels tend to be costly or available for only a small subset of stocks. For example, for a stock to be eligible for futures and options (F\&O) trading, there are additional market capitalization, free float, trading activity, and impact cost requirements. In particular, the stock has to be in the top 500 stocks based on trading activity over the previous five months, the average order size required to change the stock price by one-quarter of a standard deviation of daily returns must be less than 1,000,000 rupees; there must be at least 20\% free float and a value of at least 1 billion rupees. There are 150 stocks that are eligible for $\mathrm{F} \& \mathrm{O}$ trading at some point during our sample period (whereas 924 stocks are in the "local" sample of eligible stocks that we analyze in this paper). A shorting market also exists, but it is restricted to stocks that are eligible for $\mathrm{F} \& \mathrm{O}$ trading. Moreover, while securities are borrowed when investors sell short, short-selling does not free up capital since investors must post cash collateral equal to $100 \%$ of the value of the securities being borrowed. Investors can also borrow from non-banking finance companies (NBFCs), which are regulated by RBI (the central bank), to finance the purchase of any security. However, NBFC loans typically carry higher interest rates and other terms that are less favorable to investors. It is important to note that, even if these alternative channels are used, their existence would create a bias against finding significant effects of margin eligibility.

For eligible stocks, the most important requirements for margin trading in India are similar to those in the United States. Minimum initial margin requirements are set at 50\% (i.e., a margin trader 
may borrow up to $50 \%$ of the purchase price), and minimum maintenance margins are $40 \%$ (i.e., prices may fall without a margin call as long as the loan is less than $60 \%$ of the value of the collateral in the margin account). ${ }^{5}$ Importantly, these are minimum requirements. A broker can increase them as market conditions or their ability to provide funding changes. Margin trading rules are distinct from the other trading rules in India. ${ }^{6}$ This is important because it allows us to interpret any findings in terms of a margin trading channel, rather than something else.

\section{Data and Methodology}

\subsection{Data}

The initial sample consists of all equities trading on the National Stock Exchange of India (NSE) from April 2004 through December 2012. The master list of stocks is from the NSE. These are monthly files that contain the International Securities Identification Number (ISIN), stock symbol, impact cost measure, and the NSE group assignment for each stock. The daily stock price data are also from the NSE and include symbol, security code, closing price (in Indian Rs), high price, low price, total shares traded, and the value of shares traded. We require non-missing price and volume information for at least 12 trading days in a given month.

\footnotetext{
${ }^{5}$ For a more detailed discussion of the margin trading system in India, see the Securities and Exchange Board of India (2012). See also the referenced SEBI circular dated March 11, 2003: http://www.sebi.gov.in/legal/circulars/mar2003/circular-for-risk-management-for-t-2-rolling-settlement_15836.html.

${ }^{6}$ Group 1 membership in India has one additional regulatory advantage in the very short run. Trade settlement with the broker occurs at day $\mathrm{t}+1$. Collateral to cover potential losses prior to full payment at settlement is collected at the time of trade (this is called a VAR margin). VAR margin requirements are lower for Group 1 stocks than for Group 2 and Group 3 stocks. Thus, Group 1 stocks require less short-term capital. The existence of an additional source of leverage does not change our overall interpretation of Group 1 membership because the margin financing eligibility and the low VAR margin requirements both involve shocks to the availability of leverage, in the same direction.
} 
We obtain two datasets with information on daily outstanding margin positions. Both are from the NSE. The first dataset reports the stock-level total outstanding margin trading positions at the end of each trading day. These data are available throughout our sample period. The second dataset contains daily trader-level data with outstanding margin positions for each stock and trader. These data include unique trader and broker identification numbers and allow us to identify margin trader and broker linkages across stocks. The trader-level data are available only for the 2007 to 2010 subperiod.

There are 85,920 unique margin traders in the sample. These margin traders obtain margin debt from 19 brokers during the sample period. There is a high degree of concentration among these providers of margin debt. The Herfindahl-Hershman index, based on the average daily rupee value of margin loans, ranges from a minimum of 2,957 in 2008 to a maximum of 3,486 in 2010. The median local stock with margin debt outstanding on a given day is connected to 86 other stocks through common margin traders, with an interquartile range of 27 to 140 connected stocks. Not surprisingly, since a single broker is likely to serve more than one client, there are even more connections at the broker level. The median local stock with margin debt outstanding is connected to 415 other stocks through common brokers, with an interquartile range of 340 to 473 . Thus, cross-stock connections through margin trading are common and the question of whether they contribute to comovement during crises is of great interest. Importantly, we observe a significant decline in outstanding margin positions during the global financial crisis, consistent with the intense deleveraging commonly reported in the press. For example, from the first quarter of 2008 to the last quarter of that year, we find that outstanding margin debt declined by approximately $70 \%$. Motivated by this, we aim to 
understand whether margin trading and deleveraging cause return comovement, particularly during market downturns.

We complement the NSE data with company information from Prowess, a database of Indian firms, which covers approximately $80 \%$ of the NSE stocks. Prowess provides information on shares outstanding, index membership, ownership structure (at the quarterly frequency), and trade suspensions. Prowess data are available throughout our sample period.

Following the related studies in the literature, we impose sample restrictions to ensure data quality. First, we exclude stocks with extreme price levels (we use the $1 \%$ tails of the distribution). This restriction is similar to the restriction imposed in studies using U.S. data, which commonly focus only on stock prices above $\$ 5$ and less than $\$ 999$. Second, we exclude the stocks that have been suspended from trade, since trading irregularities in suspended stocks are likely to contaminate our returns measures. Finally, although we do not observe corporate actions such as stock splits, bankruptcy, or mergers, we remove these events from the analysis. To do so, we omit stocks with percentage changes in shares outstanding that are greater than 50\% (in absolute value) and exclude stocks with temporary ISIN identifiers, as this appears to be an indication of a corporate action.

Throughout the analysis, we focus on Group 1 and Group 2 stocks (as noted above, Group 3 stocks are not frequently traded and impact costs are also not available for this group). There are 1,842 unique ISINs in Groups 1 and 2 during our sample period.

We use daily returns for all Group 1 and Group 2 stocks to construct the comovement (corr_returns) measure for each stock and month. We define comovement as the month $t$ correlation of stock $i$ s daily returns with the market returns, where market returns are the equal-weighted average of all 
Group 1 and Group 2 stocks. We choose to equally weight the returns to construct the comovement measure in this paper in order to avoid potential bias that might result from the fact that Group 1 stocks tend to be larger than Group 2 stocks. We mainly focus on correlations rather than $\mathrm{R}^{2}$ (which is also used to capture comovement in the literature) because in principle, a high $\mathrm{R}^{2}$ can result from either a strong positive or a strong negative correlation with the market. Later in the paper, we present robustness tests using $\mathrm{R}^{2}$.

\subsection{Local Regressions: Methodology}

In the main analysis, we estimate local discontinuity regressions in which we test whether traders' leverage via margin trading impacts return comovement. We also examine how any effects that we observe vary with prevailing market conditions. To do this, we first need to define the "local" sample of stocks. Local stocks are those stocks that have impact costs that are close to the eligibility threshold of $1 \%$. To identify the appropriate local sample, one must define what "close to the threshold" means. The objective is to choose a "neighborhood" centered around the threshold (i.e., the "bandwidth") that is small enough to capture the effect of the treatment (margin eligibility), but with a sufficiently large sample to provide statistical power. To make these tradeoffs, we rely on the optimal bandwidth selection techniques in Calonico, Cattaneo, and Titiunik (CCT, 2014). The CCT bandwidths are based on the data-dependent bandwidths designed for RDD applications in Imbens and Kalyanaraman (IK, 2012), but improve on them by selecting the initial bandwidth optimally. This results in more conservative (smaller) bandwidths than those suggested by IK. The CCT bandwidth for corr_returns is 0.16 , and results in a local sample that is $90 \%$ smaller than the full sample of Group 
1 and Group 2 stocks. In robustness analysis (later in the paper), we also examine how sensitive our main findings are to the bandwidth choice.

In the final step, we estimate regressions in which the dependent variable is the monthly corr_returns for each stock in the local discontinuity sample. The basic specification is as follows:

$$
\text { Corr_returns }_{i t}=\alpha+\beta_{1}^{*} \text { Group }_{i t}+\varepsilon_{i t} \cdot(1)
$$

Group 1 is an indicator variable equal to 1 if the stock is eligible for margin trading during month $t$. The baseline regression includes a vector of year-month fixed effects. Because the dependent variable is estimated, we bootstrap all standard errors. ${ }^{7}$ Our objective in the baseline regression is to understand whether shocks (variations in margin eligibility) to the ability of traders to obtain leverage channel (margin financing) have a causal impact on comovement. The estimated coefficient on $\beta$ captures the difference in comovement for stocks that lie just above and just below the threshold and identifies the average treatment effect as long as error terms (and potentially omitted variables) are continuous at the cutoff. The identification comes from the fact that the eligibility is discontinuous at impact cost equal to $1 \%$, but variation in the other relevant variables is continuous (see, e.g., Lee and Lemieux, 2010).

Because we are primarily interested in the question of what drives the increases in comovement that we observe during crises, we remove the year-month fixed effects and add an interaction variable that captures the impact of margin trading during crises. Severedownturn is a dummy variable equal to 1

\footnotetext{
7 We use Stata's bssize command to determine the optimal number of replications. We require that our bootstrapped standard errors do not deviate from the ideal bootstrapped value (i.e., the value obtained with infinitely many replications) by more than $10 \%$ with probability 0.99 . This results in 331 replications.
} 
if monthly market returns are in the bottom decile of the monthly returns during our sample period. The main specification is as follows:

$$
\begin{aligned}
& \text { Corr_returns } \\
& \text { it } \\
& =\alpha+\beta_{1} * \text { Group }_{i t}+\beta_{2} * \text { Group }_{i t} * \text { severedownturn }_{t} \\
& +\gamma^{*} \text { severedownturn }_{t}+\varepsilon_{i t} .
\end{aligned}
$$

The primary coefficients of interest are on the Group 1 indicator variable and the Group $1{ }^{*}$ severedownturn interaction variable. If margin calls create financing frictions for margin traders, then we would expect Group 1 stocks to exhibit more comovement during times in which deleveraging affects many stocks in the market. In addition to shedding light on whether margin trading drives comovement, the relative magnitudes of the coefficients on Group $1 *$ severedownturn interaction and on the severedownturn dummy variable can tell us how much of the crisis-period increase in comovement that we observe for all stocks is caused by margin trading. ${ }^{8}$ We also estimate a model in which we replace the direct effect of severedownturn in Equation (3) with month-year fixed effects. We do this to check whether any findings from the main specification are due to unmodeled time-series variation in dependent variable.

\subsection{Descriptive Statistics}

Table 1 provides the basic summary statistics. We report market- and stock-level information for the full sample, as well as subsamples that are defined according to whether a given month corresponds to a severe market downturn. "Severe downturns" refers to months in which Indian

\footnotetext{
${ }^{8}$ Much of this paper's focus is on the differential effect of leverage during market downturns. Calonico et al. (2018a) show the conditions under which treatment interactions are consistent in regression discontinuity designs. While there is not a well-developed test for this yet, we repeat the analysis using only data from the severe downturn subsample. We do so later in the paper and find very similar results, suggesting that bias is not a concern. We would like to thank Mattias Cattaneo and an anonymous referee for suggesting the subsample analysis.
} 
market returns (i.e., CNX 500 returns) are below the $10^{\text {th }}$ decile returns, which corresponds to a onemonth market return of $-9 \%$ or less. ${ }^{9}$ Panel A of Table 1 reports that the median monthly market return during these periods is $-13.2 \%$, with an interquartile range of $-18.9 \%$ to $-10.5 \%$. "Outside of downturns" refers to all months outside of severe downturn periods. Panel A of Table 1 reports median monthly market return of $2.9 \%$, with an interquartile range of $-1.2 \%$ to $7.4 \%$, outside of severe downturns.

Panel B of Table 1 shows the summary statistics of the comovement measure for the local samples of Group 1 and Group 2 stocks. As we emphasize in the introduction, our analysis mostly focuses on these stocks, which lie near the impact cost cutoff of $1 \%$. All stocks exhibit comovement, and the average corr_returns measure is very similar for Group 1 and Group 2 stocks outside of severe downturns. The average corr_returns is 0.4254 for Group 1 stocks and it is 0.4187 for Group 2 stocks in these periods. The interesting variation appears when one examines extreme downturns. During these periods, comovement in all stocks increases. However, the effect is much larger for Group 1 stocks, for which comovement increases by $49 \%$. For Group 2 stocks, this increase is approximately 37\%. These statistics are consistent with Figure 1 Panel B, which shows the time series of comovement for the local samples. From the figure, it is clear that the average differences in comovement between Group 1 and Group 2 stocks are driven almost entirely by crisis periods. Overall, the summary statistics in Table 1 reveal important variation across margin eligibility regimes and motivate a formal examination of margin trading as a potential driver of comovement.

\footnotetext{
${ }^{9}$ In addition to capturing the recent financial crisis of 2008, this definition also captures severe market downturns that occurred in India during 2005, 2006 as well as in late 2011.
} 
We use regression analysis to test formally the hypothesis that margin trading impacts comovement; however, as Lee and Lemieux (2010) suggest, it is instructive to begin with plots of the data near the impact cost threshold. Following the RDD literature, we divide the data into impact cost "bins" and plot average comovement as a function of average impact cost within each bin. This allows for visual inspection of the data that will be analyzed more formally in the regression analysis. As noted in Section 2, the impact costs that determine eligibility in month $t$ are calculated over the six months prior to month $t$. In Figure 2, Panel A, we examine all stocks in the sample with impact costs between $0.10 \%$ and $1.90 \%$. We choose to start at $0.10 \%$ because there are very few stock-month observations with impact costs less than $0.1 \%$, especially during severe downturns. ${ }^{10}$ We form ten impact cost bins of equal width on each side of the eligibility cutoff. We choose the number of bins based on the F-tests suggested in Lee and Lemieux (2010). ${ }^{11}$ We then compute the average comovement within each bin and we run separate regressions of average comovement on average impact cost for the observations on each side of $1 \%$. We do this for all periods outside of severe downturns (left figure), as well as for periods of severe market downturns (right figure). If there is a treatment effect of margin trading eligibility, we would expect an increase in comovement at the cutoff, particularly during crisis periods.

\footnotetext{
10 There are only 6 stock-month observations with impact cost less than $0.05 \%$ during severe downturns (and only 118 stock-months with impact costs of less than $0.05 \%$ outside of severe downturns). In Panels $\mathrm{A}$ and $\mathrm{C}$ of Figure 2 , there are between 744 and 10,104 observations in each bin outside of severe downturns. During severe downturns, there are between 89 and 825 observations in each bin.

${ }^{11}$ We fail to reject the hypothesis of over smoothing when we move to ten bins from either 20 or 30 bins. We reject the null of over smoothing when we move from ten bins to five. The local sample of stocks, on which we focus in the regression analysis, approximately corresponds to the first two bins on either side of the cutoff.
} 
There is some skewness in the comovement data at the tails. In particular, stocks with very low impact cost tend to comove more with the market. This could be due to institutional ownership or index membership (both of which are higher for low impact cost stocks), or some other factor unrelated to leverage. To ensure that the patterns in Figure 2, Panel A are not being driven by outliers and to provide a closer look at the relationship between impact cost and comovement near the cutoff, Figure 2 Panel B shows only the stocks that are in the local sample. These are the observations that we use in the regressions. As in Figure 2 Panel A, we find no relationship between eligibility and comovement outside of severe downturns, and a discontinuous increase in comovement at the cutoff of $1 \%$. The latter result is even clearer once we focus on the narrower range around the eligibility cutoff.

Figure 2, Panels C and D are identical to Panels A and B (respectively) except that we replace the linear plots with polynomials of impact cost to ensure that the discontinuous jumps that we observe during downturns are not due to the linearity that we impose. ${ }^{12}$ These plots suggest a sharp jump at the cutoff. Thus, Panels A through D provide further (suggestive) evidence of the role of margin trading as a driver of comovement. The formal regression analysis described in the next section will allow for formal tests. Unlike in the bin-level average values over a wide range of impact costs shown in the, the data that we use for the regressions are stock-month observations. As in Figure 2, Panels B and D, we zoom in on the "local" stocks that lie in the region close (within one "bandwidth") to the cutoff for the regression analysis.

\footnotetext{
${ }^{12}$ We use Stata's best quadratic fit option.
} 


\section{Main Results}

\subsection{Return Comovement}

The results of the local regressions are in Table 2. We observe a small, positive coefficient on the Group 1 dummy variable when we constrain the impact of margin trading to be the same in all market environments (Column 1). The estimated coefficient of 0.012 suggests that eligibility increases comovement by 12 basis points, which is $2.76 \%$ higher than the mean of 434 basis points for the local sample of Group 2 stocks. In Column (2), when we allow the effect of eligibility to vary when the overall market experiences a severe downturn, the patterns become striking. In fact, we find that the results in Column (1) are driven entirely by severe downturn periods. The estimated coefficient on the Group 1 dummy is insignificant. Consistent with prior literature, we find that all stocks exhibit more comovement during downturns. The estimated coefficient of 0.155 on the severedownturn dummy suggests a 155 basis point increase in crisis-period comovement, representing 36.4\% and 37.0\% increases relative to the non-crisis period sample averages of 425 basis points and 419 basis points for

Group 1 and Group 2 stocks, respectively. Importantly, the positive and significant coefficient of 0.051 on the Group ${ }^{*}$ severedownturn interaction implies that those stocks eligible for margin trading display an additional 51 basis points increase in comovement. These estimates imply that margin trading accounts for approximately $27 \%$ of the total crisis-period increase for Group 1 stocks and maps to an additional 12\% increase in return comovement relative to the Group 1 sample mean outside of downturns.

As Lee and Lemieux (2010) explain, adding covariates can help reduce the sampling variability in the regression discontinuity estimates. Therefore, we add a vector of firm-level control variables to 
control for factors that are known to be correlated with measures of comovement to the specifications in Columns (1) and (2). The additional controls are one-month lagged: volatility (defined as the standard deviation of daily stock-level returns), stock-level returns, log rupee volume, market capitalization, and the lagged dependent variable. While including these covariates imposes a linearity assumption, Lee and Lemieux (2010) point out that doing so does not affect the consistency of the RD estimator. ${ }^{13}$ Results are in Columns (3) and (4) of Table 2 and are similar to those in Columns (1) and (2) except that the estimated coefficient on Group 1 becomes insignificant in Column (3) once we include the controls. Not surprisingly, we also find significant relationships between comovement and the covariates. We find that comovement is higher when stock volatility and trading volume are higher and when market capitalization is smaller. We also find that comovement is positively autocorrelated. The relationship between comovement and lagged stock returns is negative and significant, suggesting that comovement decreases when stock returns increase.

Column (5) of Table 2 shows results from the specification in which we replace the direct effect of severedownturn with month-year fixed effects. The estimated coefficient on the Group $1{ }^{*}$ severedownturn interaction is 0.046 and remains highly significant. We use the specification in Column (4) throughout the paper because it allows us to make statements about the impact of margin trading during crises relative to the average increase in comovement across all stocks during crisis periods; however, the results in Column (5) provide a useful specification check.

In Appendix Table IA.1, we also check whether the results are robust to bandwidth selection (i.e., defining the local "neighborhood" around the impact cost cutoff of 1\%). As noted earlier, we

\footnotetext{
${ }^{13}$ Before estimating the regressions, we check the extent to which covariates exhibit discontinuities at the eligibility cutoff during severe downturns. As shown in Appendix Figure IA.1, we do not observe discontinuous changes in these variables.
} 
rely on CCT bandwidths because of their optimality properties; however, it is still useful to check to see whether the results are robust to a plausible set of alternative bandwidths. The CCT bandwidth is 0.16. In Table A.1, we increase and decrease these bandwidths in increments of 0.02 (to values that are approximately 37\% greater than and less than the CCT values) and we find that the main results are robust to bandwidth choice.

Throughout the analysis, we measure comovement as the correlation of daily stock returns with market returns. However, to make sure that our results are not driven by the choice of comovement measure, we repeat the analysis using $R^{2}$ return, defined as the $R^{2}$ from a regression of the daily returns of stock $i$ on daily equal-weighted market returns during month $t$. A drawback of the $\mathrm{R}^{2}$ measure is that it captures the total comovement, which, in theory, can be due to both positive and negative return comovement. In Figure IA.2, we plot the relationship between impact cost and $R^{2}$ return. In Table IA.2, Panel B, we repeat the Table 2 analysis using $\mathrm{R}^{2}$. From the both figure and the table, it is clear that results are not dependent on the choice of comovement measure. Similar to the previous findings, we find that there is an additional 33\% increase in comovement for margineligible stocks during crisis periods.

\subsection{Additional Robustness}

We now turn to additional robustness checks to ensure that our RDD is capturing the margin trading effect. One of the identifying RDD assumptions is that there is no strategic manipulation near the cutoff. We justify this based on the margin eligibility rules that include many random order book snapshots over a six month horizons, which arguably makes manipulation difficult. However, it is 
also useful to check. If there is manipulation, we would expect to observe bunching in the data either at or just to the left of the impact cost threshold ((see Lee and Lemieux, 2010). Figure 3 shows the distribution of stocks around the eligibility cutoff (i.e., those stocks in the local sample), both outside of and during severe downturns. There is no obvious evidence of strategic manipulation at 1.00.

Another way to address concerns regarding strategic manipulation or other unusual patterns at the impact cost threshold is to estimate a "donut hole" RDD regression (Cattaneo, Idrobo and Titiunik, 2018). That is, we remove observations just to the left/right of the threshold and repeat the regression analysis. The idea behind a "donut hole regression" is that we can conduct analysis in which we remove those observations and check to see whether the results are sensitive to these observations. In Table 3, Panel A, we begin with the CCT bandwidth of $0.16 \%$ and we shrink it by $5 \%$ by eliminating observations within $0.008 \%$ of the threshold (Column 1 ) and by $10 \%$ by eliminating all observations within $0.016 \%$ of the threshold (Column 2). The economic and statistical significance of the estimated coefficients are very similar those of Table $2 .{ }^{14}$

The focus in this paper is on the Group $1{ }^{*}$ severedownturn interaction, which captures the differential effect of margin eligibility during downturns. Calonico et al. (2018) show the conditions under which treatment interactions like this one are consistent in regression discontinuity designs. Because there is still no well-developed test for consistency, we can check for robustness by repeating the main analysis using only data from the severe downturn periods. That is, we estimate Equation (1) using data only from the severe downturn subsample. The estimated coefficient on the Group 1 dummy provides an estimate of the excess comovement of Group 1 stocks during severe downturns.

\footnotetext{
14 Internet Appendix Table IA.2, Panel C shows donut hole regressions using the alternative comovement measure. Results are similar.
} 
The specification does not allow us to make statements about the extent to which margin trading drives the crisis-period increases in comovement (relative to normal times) because the intercept captures both average comovement and the average crisis-period increases in comovement, but it still allows us to compare levels of crisis-period comovement across margin eligible and ineligible stocks. The results are in Table 3, Panel B. The results are very similar to the main findings in that the estimated coefficient of Group 1 is 0.056 in Column (2), whereas the coefficient of Group $1{ }^{*}$ severedownturn in the corresponding specification in Column (4) of Table 2 is 0.055.

We also confirm that our main findings are robust to using local polynomial regressions, in which we control for polynomials of impact cost. We follow Lee and Lemieux (2010) and use the Akaike information criterion (AIC) to determine the appropriate polynomial orders for a given bandwidth. This approach helps avoid the overfitting problem that can result from estimating polynomial regressions over very narrow bandwidths. We begin with the CCT bandwidth used in main regressions, and we expand it by factors of 1.25 to 1.75 . The AIC suggests polynomial orders ranging from 1 to 3 for these bandwidths. Results are reported in Table 3, Panel C and show that the inclusion of these polynomials does not have an important impact on our findings. The findings are similar if we limit the analysis to severe downturn periods only and repeat the local polynomial regressions. These results are reported in Appendix Table IA.3.

The RDD is powerful in that any variation in comovement that we observe close to the eligibility threshold should be due to margin trading. Still, there are some potential alternative mechanisms that warrant discussion. Barberis et al. (2005) find that index membership is associated with higher comovement. Boyson, Stahel, and Stulz (2010) and Billio, Getmansky, Lo, and Pelizzon 
(2012) link hedge funds to comovement. Unlike the margin trading channel (a type of trader leverage related to funding constraints), these variables capture effects due to similarity in institutional investment styles. In interpreting the results in this paper, one might be concerned that Group 1 status is capturing variation in institutional (or even foreign) ownership rather than margin trading. Another potential explanation for our results is that Group 1 status is a proxy for the ability to trade derivatives or short the stock. We consider whether these alternative channels drive the main results.

To examine whether our results are driven by index membership, we introduce a dummy equal to 1 if the stock is in the CNX500 index (Standard and Poor's broad-based index of the Indian Stock market). To investigate the role of investor type, we use quarterly ownership data from Prowess and introduce variables foreign and inst, which equal to the percentage foreign and institutional ownership, respectively. We also introduce deriv, a dummy variable equal to 1 if the stock is eligible for futures and options trading. Note that deriv also maps one-to-one with shorting eligibility. ${ }^{15}$ In Table 3, Panel $\mathrm{D}$ we repeat the analysis shown in Table 2 , but we include the proxies for alternative channels. ${ }^{16} \mathrm{We}$ also interact them with the Group 1 dummy, as well as the Group $1{ }^{*}$ severedownturn interaction variable, to see whether our margin trading interpretation is actually coming from an alternative mechanism. While some of these alternative interpretations are significant on average, none of them have a differential impact on return comovement during severe downturns. Most importantly, the estimated

\footnotetext{
${ }^{15}$ Note that all stocks eligible for futures and options trading are in Group 1; however, it is only a subset of margin-eligible stocks (there are approximately 150 of these stocks over the entire sample period). This means that the group $1 *$ deriv and deriv are collinear. Thus, the former are dropped from the analysis.

${ }^{16}$ In Appendix Figure IA.3, we plot the alternative channel variables as a function of impact cost. The plots do not reveal discontinuities at 1\%. The regressions in Table IA.4 confirm that there are no discontinuities.
} 
crisis-period impact of Group 1 status on return comovement remains very close to the main results in Table 2.

The identifying assumption in the causal interpretation of our findings is that there is a sharp discontinuity in the ability of traders to borrow at the impact cost value of $1 \%$. One potential alternative interpretation of the main results is that the measured impact costs predict future return comovement rather than variation in margin trading and that the regressions capture this relationship. The polymomial regressions addresses this concern; however, we can also conduct placebo tests. To ensure that our results are not driven by variation in impact cost, we repeat the analysis around false eligibility cutoffs: the first at one bandwidth above, and the second at one bandwidth below, the true cutoff of $1 \%$. The results are in Table 4 and, consistent with the causal interpretation, we find no impact of eligibility at the false cutoffs.

\section{Mechanism Tests}

The results in Table 3, Panels A through D, and in Table 4 confirm a robust, causal effect of eligibility on excess comovement during crises. The goal of this section is to uncover the mechanisms driving the main results.

\subsection{Downside Volatility or Upside Volatility?}

What happens during other periods of high market volatility, specifically when there are large rises in the market? If the main findings are due to margin traders whose portfolio constraints cause deleveraging when market conditions deteriorate, we would not expect to observe symmetric effects 
during extreme up- and down- market conditions. Examining market rallies, rather than severe downturns, can serve as a check for the mechanism driving our results. In Table 5, we repeat the Table 2 regression analyses, but we replace severedownturn with market_rally, a dummy variable equal to 1 if market returns are higher than $90^{\text {th }}$ percentile returns. There are two important observations from the table. First, on average, return comovement is lower during extreme market increases. Second and most importantly, there is no differential impact of margin eligibility on comovement during market rallies, that is, the coefficient on the market_rally*Group 1 interaction is insignificant. The effect that we document is specific to downturns. These findings support the leverage-induced funding constraints interpretation of our main results.

\subsection{Pairwise Analysis of Within-Group Comovement}

If the increased comovement that we observe in Group 1 stocks during severe downturns is due to binding margin constraints and deleveraging, then one would expect comovement to be higher within the universe of Group 1 stocks. In this section, we analyze comovement within and across Group 1 and Group 2 stocks. To do so, we calculate the pairwise correlations in stocks' returns, and test whether within- or across-group comovement is stronger. The increase in correlations in all stocks that are due to crisis periods are captured by the severedownturn dummy. We are interested in the interaction effects.

For each local stock, we calculate the monthly pairwise correlations of the stock's daily returns with the daily returns of all other stocks in the market (including nonlocal stocks). Corr_return is the monthly pairwise correlation in stock returns. We analyze the differences in pairwise correlations for 
different types of stock pairs. G1G1 is a dummy variable equal to 1 if both stocks in a given pair are Group 1 members; G2G2 is a dummy variable equal to 1 if both stocks in a given pair are Group 2 members. The baseline pair is a pair that consists of one Group 1 and one Group 2 stock. We interact both G1G1 and G2G2 with severedownturn dummy to assess the change in within-group pairwise correlations during downturns. The results are in Table 6, Column 1. Consistent with our previous findings, all stocks exhibit heightened comovement during severe downturns. Group 1 stocks, which are susceptible to margin constraints have higher pairwise correlations with other stocks, especially during downturns. Most importantly, in those crisis periods, Group 1 stocks have higher pairwise return correlations with other Group 1 stocks than they do with Group 2 stocks (G1G1 and G1G1 * severedownturn are both positive and significant). Thus, the findings in earlier tables not only reflect Group 1 stocks' increased comovement with the market, but that some of this stems from increased comovement with other Group 1 stocks. In Column (1) of Table 2, the baseline pair is a Group 2 stock paired with either a local Group 2 stock or a local Group 1 stock. In Column (2) of Table 6, we repeat the analysis including G2G2 (and its interaction term with severedownturn), thus the baseline pair consists of one Group 1 stock and one Group 2 stock. The table shows that Group 2 stocks, which are ineligible for margin trading and less likely to have traders facing margin constraints, see less pairwise return comovement with other Group 2 stocks in both normal times and during crises. The estimated coefficients on G1G1 and $G 1 G 1^{*}$ severedownturn are similar to those in Column (1). Column (3) is identical to the analyses identical to Column (2) except that we require both stocks in the pair to be in the local sample. The results are in line with those in Columns (1) and (2). 
What drives the crisis-period effects that we observe in Table 6, Columns (1) through (3)? Is it traders' use of leverage or is it simply the eligibility status? If the former, we would expect the comovement to be greater for stocks that experience correlated trading of margin positions. The daily stock-level margin positions data available in India allow us to examine this question. We calculate a proxy for correlated margin trading activity: margin corr, which equals the pairwise correlation in daily margin trading positions for Group1 stocks (this variable equals zero for pairs that include Group 2 stocks)during each month. This variable is zero for pairs that include Group 2 stocks. We test whether the G1G1 effects that we document stem from correlated margin trading. Results are in Table 6, Columns (4) and (5). Indeed, we find that correlated crisis-period margin trading implies higher comovement. The estimated coefficient of 0.0403 implies that a one standard deviation in margin corr results in a an additional 8-9\% increase in comovement for Group 1 stocks during severe downturns.

\subsection{Return Comovement: Trader versus Broker Connections}

We obtain trader-level margin positions data from the NSE for the 2007 to 2010 subperiod to dive deeper into the idea that common margin traders in Group 1 stocks play an important role in crisis-period comovement. ${ }^{17}$ These data are far richer than the monthly market-level margin debt outstanding data available from U.S. exchanges like the NYSE and allow us to conduct deeper analyses of the impact of connections that stocks have via levered traders and their brokers. For each stock and each trading day, we observe all traders' individual end-of-day margin trading positions, along

\footnotetext{
${ }^{17}$ In Table IA.4, we repeat the Table 6 analysis using just the 2007-2010 period to ensure that the basic relationships that we have documented so far hold in the data for which we are able to analyze trader and broker connections. The results in Table IA.4 are very similar to those in Table 6.
} 
with unique trader and broker identification numbers. These unique identifiers allow us to identify all of the stocks financed with margin debt by each individual trader, as well as the broker that she uses.

Both the trader and broker connections are of interest. At the trader level, it is possible that a margin constraint will force a given trader to liquidate positions in many stocks in her portfolio at once. At the broker level, a negative shock to the overall market might make the broker less willing and able to provide capital to its customers. Both are related to funding constraints, stemming from stress at the trader- and broker-level, respectively. Our data allow us to provide causal evidence of both of these channels. To our knowledge, our paper is the first to do so.

Using the detailed margin position data, we examine the role of stock-level connectedness through margin trading on return comovement. We construct our measures of stock-level connectedness in the spirit of Anton and Polk (2014) and Bartram, Griffin, Lim, and Ng (2015). We define Common traders, which is the total value of the margin trading positions held by all common margin traders of the two stocks scaled by the total market capitalization of the two stocks. Similarly, Common broker is defined as the total value of the margin trading positions lent out by all common brokers of the two stocks scaled by the total market capitalization of the two stocks. These measures are defined for pairs of stocks which are both Group1 members (this is because only Group 1 stocks are eligible for margin trading). Specifically, the measures capture pairwise connections between the local Group1 stocks and all the other Group 1 stocks in the market. Both Common traders and Common broker are monthly averages of daily values and are normalized to have zero mean and unit standard deviation so that it is straightforward to compare their coefficients. As in the Table 6 analysis, dependent variable is the monthly pairwise correlation in stocks' returns, Corr_return 
Results are reported in Table 7 . In Column (1), we regress pairwise return correlations on Common traders, the severedownturn dummy, the Common traders*severedownturn interaction, as well as the G1G1 dummy and its interaction with severedownturn. In Column (2), we focus on Common broker, severedownturn, and their interaction. In Column (3), we include both the Common traders and Common broker variables to test whether one effect dominates. Columns (1) and (2) suggest that both Common traders and Common broker are associated with higher return correlations on average, and these effects become much larger during severe market downturns. Interestingly, the magnitudes of the coefficients on the Common broker variable during these periods are about twice those of Common traders. When we run a "horserace" between the two potential effects, we find that the common broker channel drives the correlations that we observe. In Column (4), we focus only on stock pairs in which both stocks are in the local sample of Group 1 stocks. While the sample size is much smaller, the impact of common brokers remains. The estimated coefficient of 0.027 implies that a one standard deviation increase on the common broker variable results in an additional $12 \%$ increase in pairwise correlations during severe downturns.

\subsection{Evidence from Trades: Trader versus Broker Portfolio Spillovers}

We conjecture that the broker (and, to a lesser extent, the trader) effects that we observe in Table 7 can be due to portfolio pressures during downturns that cause margin traders to unwind their positions, resulting in downward pressure on the prices of stocks in their portfolios. In this section, we provide direct evidence of this mechanism. To this end, we conduct an analysis of the relationship between margin trading in stock $i$ and the recent portfolio returns of all traders and brokers who are 
connected to stock $i$. In Table 8, we focus the analysis only on Group 1 stocks and we examine daily margin trading activity at the stock level. The proxy for margin trading is ch_margin, the percentage change in total margin positions from day $t-1$ to day $t$ in stock $i$. We regress $c h \_m a r g i n$ on 5 -day lagged trader and broker margin loan portfolio returns. To calculate trader portfolio returns, we first take the value-weighted average of margin portfolio returns (over all stocks held on margin) of each trader over trading days $t-5$ through $t-1$. We then aggregate to the stock level and we define trader portfolio ret as the value-weighted average of the past 5-day returns of all traders with margin positions in a given stock, where weights are calculated as the trader's investment in the stock, divided by the stock's total outstanding margin positions. To calculate broker portfolio returns, we first take the valueweighted average of trader portfolio returns (over all stocks held on margin) of the clients of a a given broker over trading days $t-5$ through $t-1$, where weights equal the value of each client's total margin positions divided by the total amount lent out by the broker. We then aggregate to the stock level and we define broker porffolio ret as the value-weighted average of past 5-day client portfolio returns of all brokers that provide margin financing in the stock, where weights equal the value of each broker's total margin loan in the stock, divided by the stock's total outstanding margin positions. The regressions are performed at the stock-day level. We also control for stock $i$ s 5-day lagged returns as well as the 5-day market return in extended specifications. Results are in Table 8.

Table 8 shows the relationship between margin trading in stock $i$ and the recent portfolio returns of all traders and brokers that are connected to stock $i$. Trading that follows portfolio returns at either the broker or trader level is evidence that the correlated returns that we observe are due, at least in part, to spillovers that stem from margin debt. In Column (1), we examine trader_portfret and 
find that traders tend to increase their margin positions following positive portfolio returns and they decrease them during downturns. But we do not find a significant interaction between trader_portfret and severedownturn. When we add broker_portf_ret to the specification in Column (2), we see that the positive and significant estimated coefficient on trader_portf_ret in Column (1) was due to broker, not trader effects. More importantly, the positive and significant estimated coefficients on both broker_portfolio_ret and broker_portf_return ${ }^{*}$ severedownturn establishes that margin positions tend to decrease as brokers' clients returns decrease. This effect is even larger during severe downturns. In fact, the negative and significant coefficient on the severedownturn dummy that we observe in Column (1) becomes insignificant in Column (2), suggesting that the crisis-period effects are coming through broker portfolio return spillovers.

Columns (3) and (4) of Table 8 are identical to Columns (1) and (2) except we refine the definitions of trader_portf_ret and broker_portfolio_ret to exclude stock $i$. In the new definitions, trader portfolio ret excludes stock $i$ and brokerportfolio ret excludes all clients holding stock $i$. We add stock_i_ret, defined as the 5-day lagged returns as an additional explanatory variable. We also interact stock_i_ret with severedownturn. This specification provides the cleanest test of spillover effects, given that any direct own-stock effects are separate from trader_portf_ret and broker_porffolio_ret. We find that, on average, margin traders are contrarian with respect to stock $\imath$ 's past returns, and importantly, that the estimated coefficients on the broker and trader portfolio variables are qualitatively similar to what we observe in Columns (1) and (2). Finally, in Columns (5) and (6), we add market_ret (5-day lagged market returns), the interaction of market_ret returns with severedownturn, and stock fixed effects. The broker portfolio spillover effect is robust to the inclusion of these additional controls. Overall, the 
important observation from Table 8 is that portfolio spillovers matter, and that the broker channel is much more important than the trader channel. This provides direct evidence supporting the findings of Table 7.

Next, we take a closer look at the spillovers documented in Table 8 to explicitly examine the effects arising from losses. To this end, in Table 9, we extend the regressions in Column 6 of Table 8 by introducing four new variables to capture trader and broker constraints. Constrainedbroker equals broker_portfolio_ret if broker_portfolio_ret is negative, and zero otherwise. Constrainedtrader equals trader_portfolio_ret if trader_portfolio_ret is negative and zero otherwise. Very_constrained_broker equals 1 if broker_porffolio_ret is less than the $10^{\text {th }}$ percentile of all broker_portfolio_ret observations in sample. Very_constrained_trader equals 1 if trader_portfolio_ret is less than the $10^{\text {th }}$ percentile of all trader_portfolio_ret in sample. These new variables capture broker and trader losses. From Table 9 (in particular, the last column), we see that all of the Table 8 results stem from large broker losses. This provides direct evidence in support of the "margin spiral" channel described in Brunnermeier and Oehmke (2013).

\subsection{Broker Characteristics and Excess Comovement during Severe Downturns}

To further the investigation of the mechanisms driving the main result, we dive deeper into the broker effects that we observe during severe downturns. In particular, we ask whether there are important broker characteristics that can inform the interpretation of the economic mechanisms driving excess comovement during crisis periods. In Table 10, we focus the analysis on severe downturn periods (for brevity) and we examine the relationship between daily stock returns and various broker characteristics. The dependent variable is stock $\imath$ 's day $t$ return. Explanatory variables 
include Group1_ret, the equal weighted average day $t$ stock return of all Group 1 stocks (excluding stock i), a broker characteristic, and Group1_ret interacted with the broker characteristic.

The broker characteristics are: Brokersize, Client HHI, ClientPortfHHI, Stock HHI, BrokerVol, and Broker Illiq. Brokersize is the value weighted average of the size of all brokers whose clients have margin debt in a given stock. Whether the crisis period effects are driven by large or small brokers is an empirical question. As Brunnermeier and Oehmke (2013) argue, "a group of 100 institutions that act in a correlated fashion can be as dangerous to the system as one large entity." BrokerVol is the month $t-1$ value-weighted average volatility for all stocks for which brokers connected to stock $i$ provide margin financing and BrokerIlliq, the month $t-1$ value-weighted average Amihud (2002) illiquidity measure for all stocks for which brokers connected to stock $i$ provide margin financing. Brunnermeier and Petersen (2009) show that higher asset volatility causes brokers to tighten margin requirements as intermediaries aim to minimize their losses by using value-at-risk method to set the margins. Asset illiquidity can have a similar effect as potential losses are larger if brokers seize stock collateral that are illiquid and therefore costly to trade. Client HHI is the day $t$ client HerfindahlHirschman Index (HHI), calculated as the sum of the square of each client's share of a broker's outstanding margin loans. Higher client concentration implies that each individual client has more weight in the broker's portfolio. When brokers have exposure to only a few clients, we expect them to be more sensitive to constraints. ClientPortfHHI is the sum of the squared shares (HHI) of each stock in a brokers' clients' portfolios. The HHI is first calculated for each client, and then ClientPortfHHI is the weighted average of the client HHI, where weights are given by the total value of a client's margin debt divided by all of the broker's margin loans. When clients have more 
concentrated portfolios, their portfolios are riskier. This might cause more crisis-period tightening of margin requirements by brokers. Stock $H H I$ is the sum of the squared shares of all stocks lent out by a broker, where share is defined as the value of margin financing lent out by a broker for stock $i$, divided by all of the broker's outstanding margin loans. This variable can capture potential tightening due to an undiversified portfolio of margin loans. Each of the broker characteristics variables is normalized to have a zero mean and unit standard deviation so that coefficients can be easily compared.

From Table 10, there are a few important observations. First, the positive and significant coefficient on Group1_ret shows the high correlation in returns during downturns. This is consistent with the main results in Table 2. Second, the cross-sectional broker variables exhibit significant interactions with Group1_ret. The correlation of a given Group 1 stock's returns with other Group 1 stocks is higher when brokers are large, indicating that large brokers are in fact systemically more important than the small ones. Of the remaining broker characteristics, we find that correlations are higher when the stocks for which brokers provide margin financing are more volatile and more illiquid, when there is more concentration in the broker's client base, clients' portfolios and the stocks for which they are providing margin loans. When we compare the magnitudes of these effects, we find that broker portfolio volatility has the most significant effect economically. This is precisely the mechanism in Brunnermeier and Pedersen (2009). 


\subsection{Extended Discussion}

To summarize, the main finding in this paper is that return comovement increases substantially during crisis periods for margin-eligible stocks. It is worthwhile to discuss external validity and the extent to which these results can be generalized outside of the Indian market setting. While difficult to fully rule out these concerns, we do not believe that they should be central to the overall interpretation. This is because our finding that margin-eligible stocks experience substantial increases in comovement during severe downturns is consistent with the same underlying mechanisms that are relevant to both developed and emerging markets. The fact that some of our findings line up qualitatively with new evidence from Chinese markets in Bian, Da, Lou, and Zhou (2018) highlights the relevance of the margin trading mechanism worldwide.

\section{Conclusion}

In this paper, we exploit the features of the margin trading system in India to test whether there is a causal effect of margin trading on stock return comovement. Consistent with the mechanism described in Brunnermeier and Oehmke (2013), margin trading does not have an impact during normal times, but it substantially amplifies return comovement during crisis periods. Moreover, we find that margin-eligible stocks that are more connected, through common brokers, experience much larger crisis-period increases in pairwise comovement. This is driven, at least in part, by recent losses in brokers' margin loan portfolios.

Our analysis provides a direct test of the hypothesis that margin trading exacerbates the crisisperiod increase in return comovement. Importantly, the regression discontinuity design allows us 
isolate the impact of margin trading from confounding effects - an empirical challenge that has been faced by previous studies. Our findings should help policymakers and researchers who are interested in identifying effective tools in preventing the peaks in return comovement that we observe during periods of high market stress. 


\section{$\underline{\text { References }}$}

1. Anton, M., and Polk, C. (2014) Connected stocks, Journal of Finance 69, 1099-1127.

2. Barberis, N., Shleifer, A. and Wurgler, J. (2005) Comovement, Journal of Financial Economics 75, $283-317$.

3. Bekaert, G., Harvey, C., and Ng, A. (2005) Market integration and contagion, Journal of Business 78, 39-69.

4. Bian, J., Da, Z., Lou, D., and Zhou, H. (2018) Leverage networks and market contagion, working paper.

5. Jiangze, B., He, Z, Shue, K., and Zhou, H. (2017) Leverage-induced fire sales and stock market crashes, working paper.

6. Billio, M., Getmansky, M., Lo, A. W., and Pelizzon, L. (2012) Econometric measures of connectedness and systemic risk in the finance and insurance sectors, Journal of Financial Economics 104, 535-559.

7. Boyson, N. M., Stahel, C. W., and Stulz, R. M. (2010) Hedge fund contagion and liquidity shocks, Journal of Finance 65, 1789-1816.

8. Brunnermeier, M., and Oehmke, M. (2013) Bubbles, financial crises, and systemic risk, Chapter 18 in the Handbook of the Economics of Finance. Amsterdam: Elsevier.

9. Brunnermeier, M., and Pedersen, L. (2009) Market liquidity and funding liquidity, Review of Financial Studies 22, 2201-2238.

10. Calonico, S., Cattaneo, M. D., and Titiunik, R. (2014) Robust nonparametric confidence intervals for regression discontinuity designs, Econometrica 82, 2295-2326. 
11. Calonico, S., Cattaneo, M. D., Farrell, M. H. and Titiunik, R. (2018) Regression discontinuity designs using covariates, Review of Economics and Statistics (forthcoming).

12. Cattaneo, M. S., Idrobo, N. and Titiunik, R. (2018) A practical introduction to regression discontinuity designs: Volume I, Monograph prepared for Cambridge Elements: Quantitative and Computational Methods for Social Sciences. Cambridge University Press.

13. Chung, J. and Kang, B. U. (2016) Prime broker-level comovement in hedge fund returns: Information or contagion? Review of Financial Studies 29, 3321-3353.

14. Fong, K., Holden, C. W., and Trzcinka, C. A. (2014) What are the best liquidity proxies for global research? Working paper.

15. Geanakoplos, J., (2010) The leverage cycle, NBER Macroeconomics Annual 2009, 1-65. University of Chicago Press.

16. Gromb, D. and Vayanos, D. (2009) Leverage and liquidity dry-ups: A framework and policy implications, working paper.

17. Gromb, D. and Vayanos, D. (2002) Equilibrium welfare in markets with financially constrained arbitrageurs, Journal of Financial Economics 66, 361-407.

18. Hameed, A.., Kang, W., and S. Viswanathan, S. (2010) Stock market declines and liquidity, Journal of Finance 65(1), 257-293.

19. Imbens, G., and Kalyanaraman, K. (2012) Optimal bandwidth choice for the regression discontinuity estimator, Review of Economic Statistics 79(3), 933-959.

20. Jotikasthira, C., Lundblad, C. and Ramadorai, T. (2012) Asset fire sales and purchases and the international transmission of funding shocks, Journal of Finance 67(6), 2015-2050. 
21. Kahraman, B., and Tookes, H. E. (2017) Trader leverage and liquidity (2017), Journal of Finance $72,567-1610$.

22. Kyle, A.S.., and Xiong, W. (2001) Contagion as a wealth effect of financial intermediaries, Journal of Finance 56, 1401-1440.

23. Lee, D.S., and Lemieux, T. (2009) Regression discontinuity designs in economics, NBER Working Paper 14723.

24. Morris, S. and Shin, H. S. (2004) Liquidity black holes, Review of Finance 8, 1-18.

25. Securities and Exchange Board of India, Annexure 1, Master Circular for Stock Exchanges on Trading Part 1, March 12, 2012.

26. Weill, P. (2007) Leaning against the wind, Review of Economic Studies 74, 1329-1354. 


\section{Figure 1. Time Series of Return Comovement}

Panel A shows the time series of the (equal-weighted) average comovement of all Group 1 and Group 2 National Stock Exchange (NSE) stocks during April 2004- December 2012. The figure in Panel B shows the time series of the (equal-weighted) average comovement in the local samples of Group 1 and Group 2 stocks during April 2004- December 2012. The comovement measure is corr_returns, which is defined as the month $t$ correlation of stock $i$ s daily returns with the market returns. The figure also shows the CNX 500 returns, which is Standard and Poor's broad-based index of the Indian stock market.

Panel A Full Sample

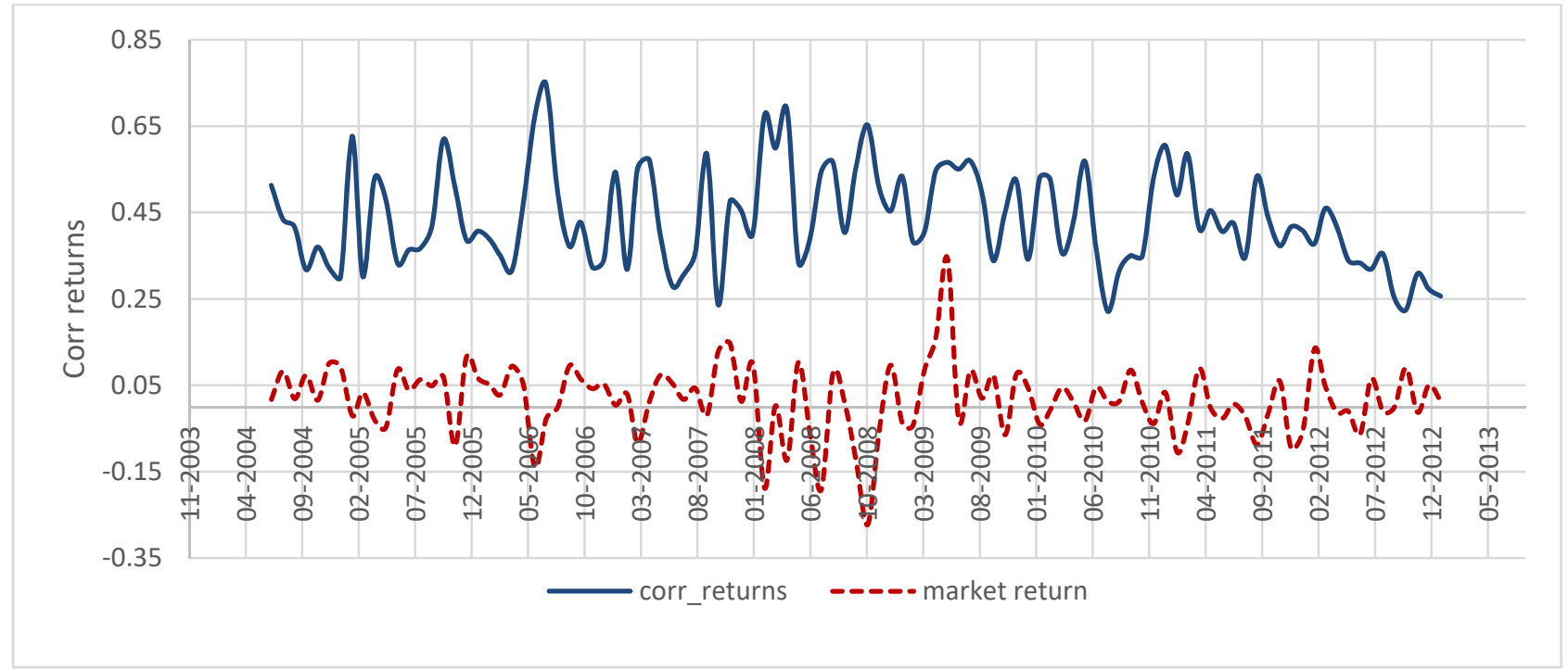

Panel B Local Sample of Group 1 and Group 2 Stocks

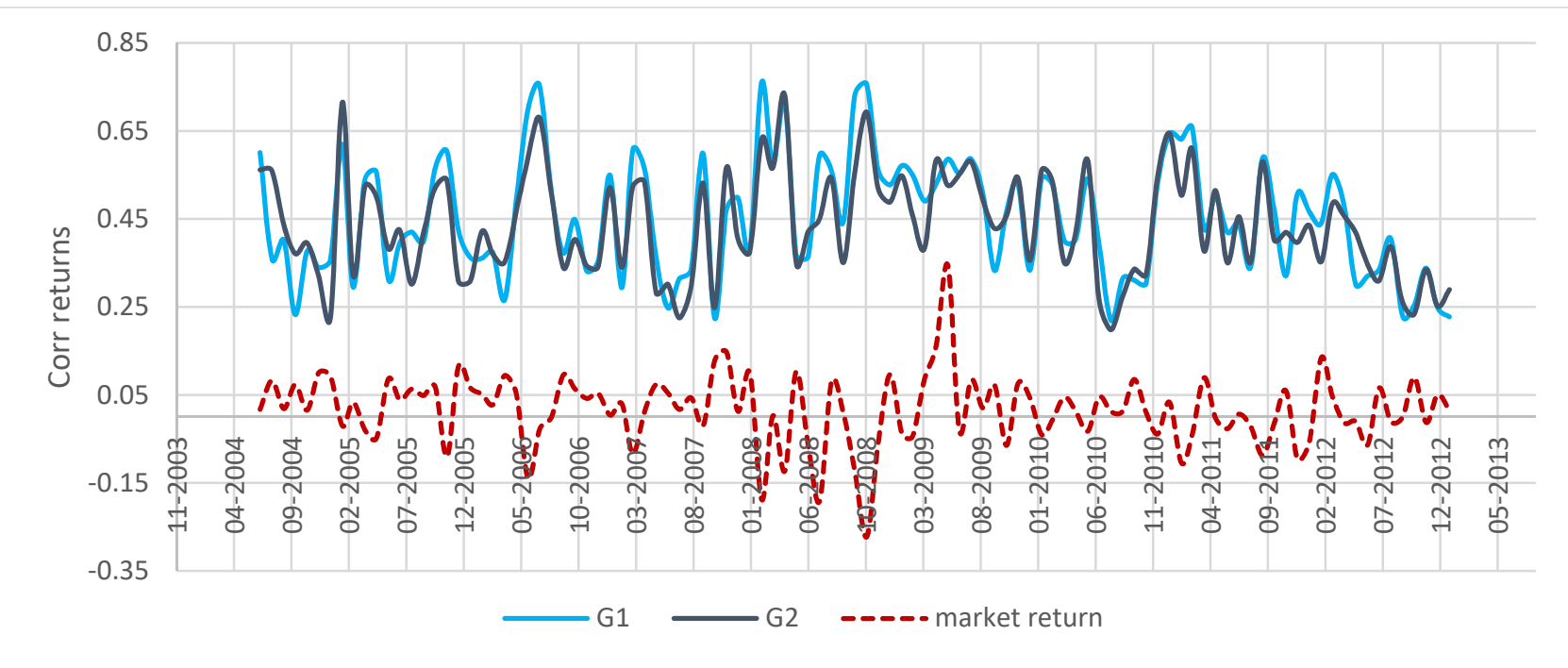




\section{Figure 2. Impact Cost and Comovement}

The figures plot the average return comovement during month $t$ as a function of impact cost over the previous six months (which determines month $t$ eligibility). The comovement measure is corr_returns, which is defined as the month $t$ correlation of stock $i$ s daily returns with the (equal-weighted) average daily market returns. Stocks are divided into equally sized bins (the $\mathrm{X}$ axis) on each side of the eligibility cutoff of $1 \%$. The figures show the average comovement within each bin. The number of bins (10) is chosen based on the F-test procedures described in Lee and Lemieux (2010). Margin eligible stocks are all those stocks with impact costs that are less than or equal to $1 \%$, and are located to the left of the vertical line. "Severe downturns" refers to months in which market returns are below the 10th percentile returns. Panel A shows the bins over the range of $0.1 \%$ to $1.9 \%$. Panel B shows the bins over the range of $0.25 \%$ to $1.75 \%$ (the local sample of stocks used in the regression analyses). Panels $\mathrm{C}$ and $\mathrm{D}$ are identical to Panels $\mathrm{A}$ and $\mathrm{B}$ (respectively), but instead of linear plots, we use the best polynomial fit of the data.

Panel A
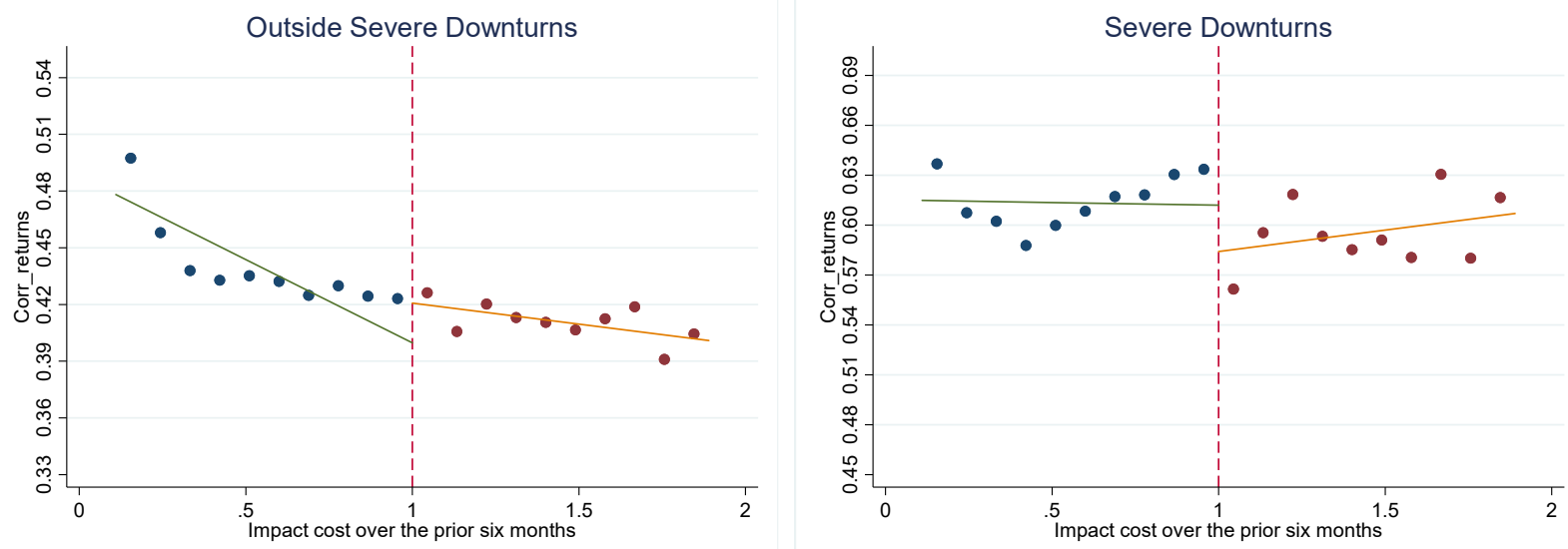

Panel B
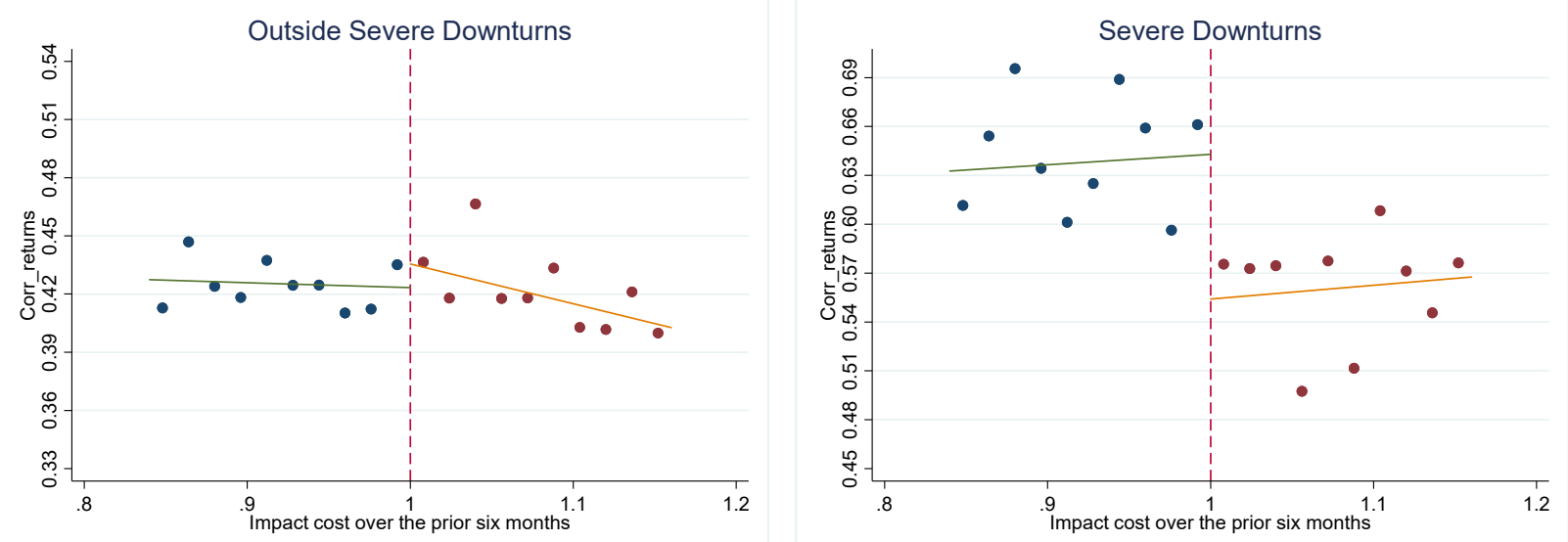
Panel C
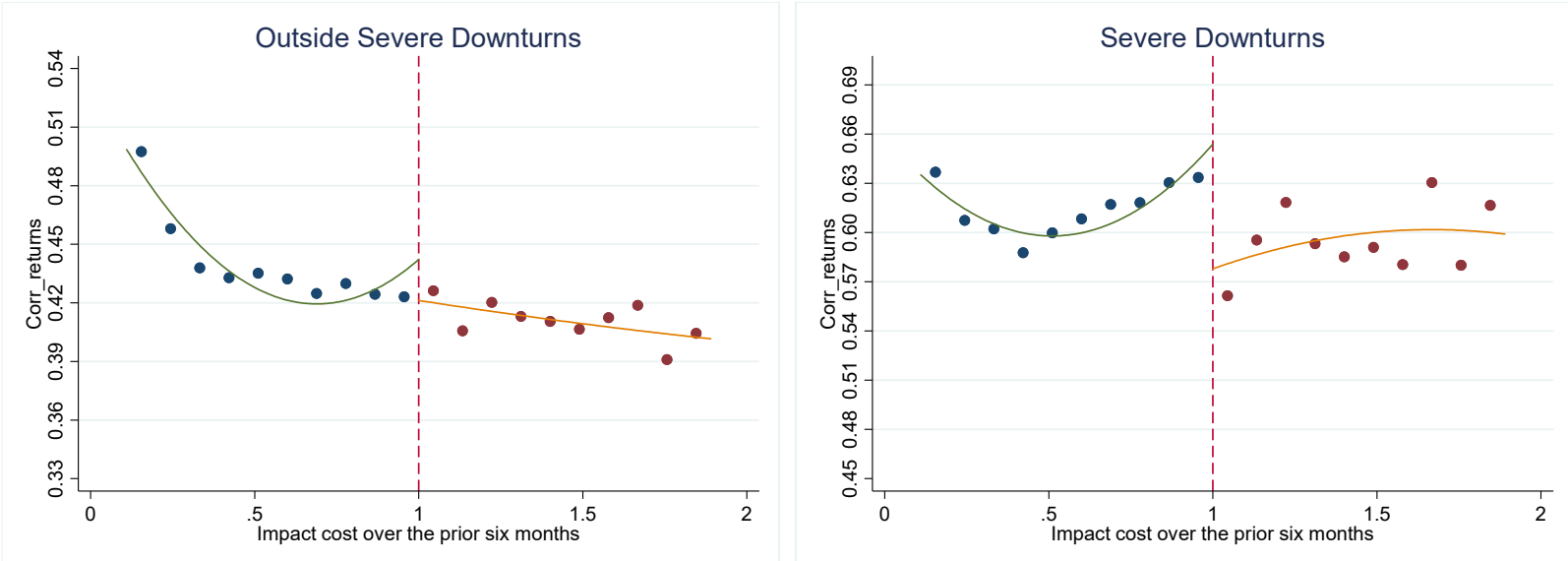

Panel D
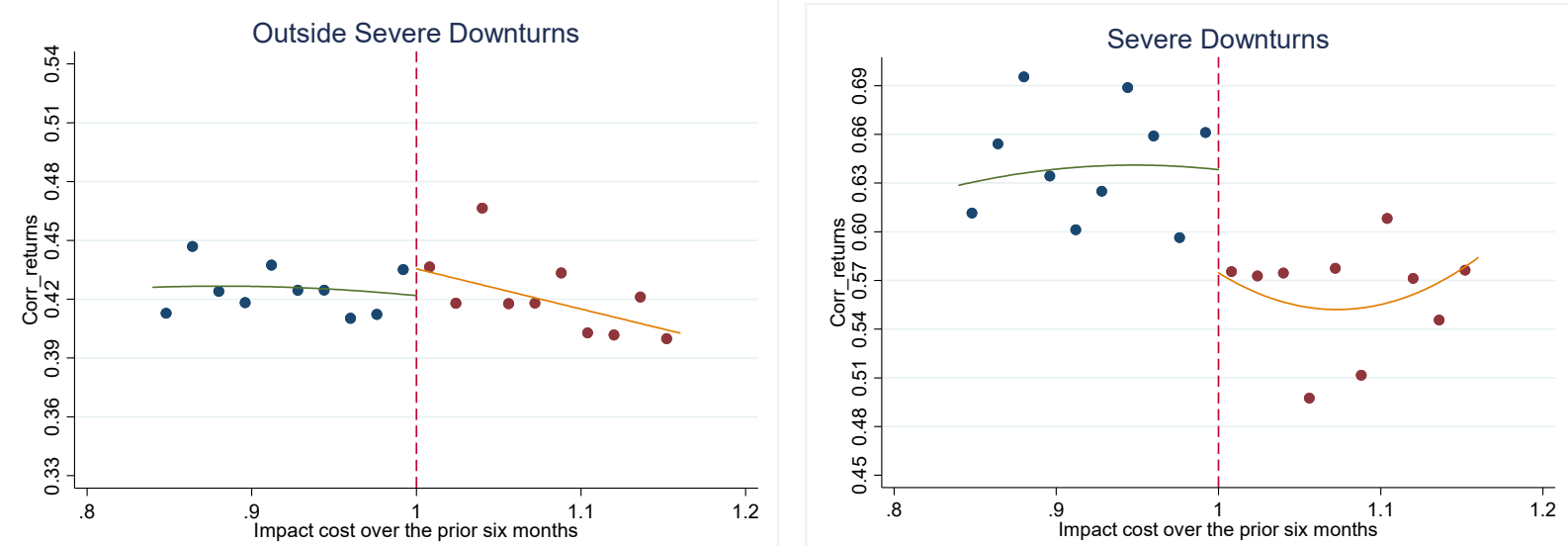


\section{Figure 3. Distribution of Stocks around the Eligibility Cutoff}

Figures show the number of stock-month observations in each impact cost bin (of size 0.01) near the margin trading eligibility cutoff of $1 \%$ (i.e., for the local sample of stocks). "Severe downturns" refers to months in which market returns are below the 10th percentile returns.
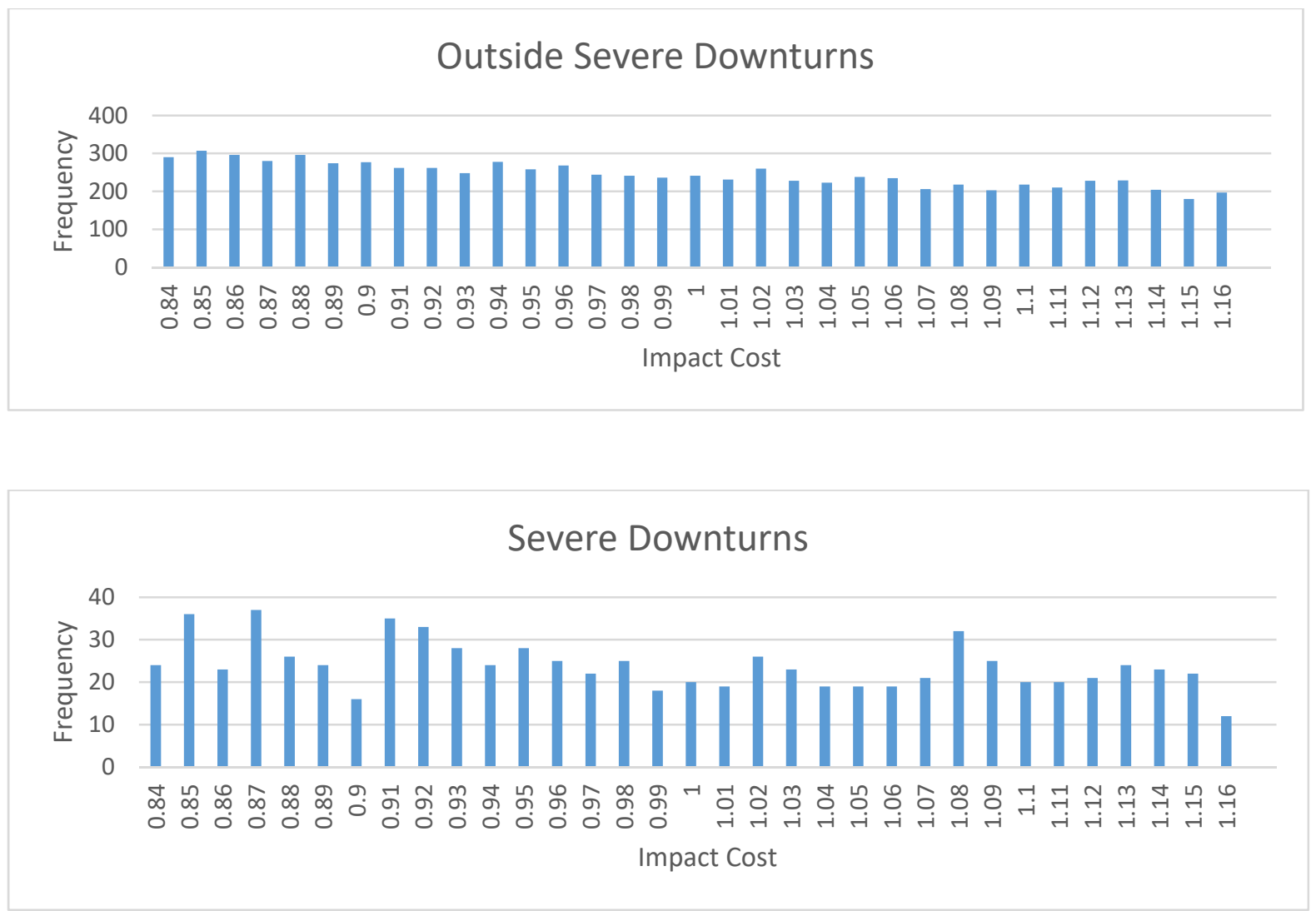


\section{Table 1. Descriptive Statistics}

This table provides summary statistics of market stock returns and stock-level return comovement. The sample period is from April 2004 through December 2012. Summary statistics are reported for the full sample, and for the subsamples that are defined according to market conditions. "Severe downturns" refers to months in which market returns (i.e., CNX 500 returns) are below the $10^{\text {th }}$ percentile returns. "Outside of downturns" refers to all months outside of severe downturns. Panel A provides summary statistics for market returns; Panel B provides summary statistics of return comovement for the local samples of Group 1 and Group 2 stocks, where the local samples are defined based on the CCT bandwidth of $0.16 \%$. Corr_returns is defined as the month $t$ correlation of stock $i$ 's daily returns with the (equal-weighted) average daily market returns. All variables are monthly.

\begin{tabular}{llccccc}
\hline \multicolumn{7}{c}{ Panel A: Market Returns } \\
\hline \multirow{3}{*}{ Full sample } & Variable & Mean & Median & P25 & P75 & Std Dev \\
Severe downturns & Mkt ret & 0.0145 & 0.0166 & -0.0287 & 0.0679 & 0.0830 \\
Outside of downturns & Mkt ret & -0.1515 & -0.1317 & -0.1878 & -0.1045 & 0.0572 \\
& Mkt ret & 0.0322 & 0.0290 & -0.0123 & 0.0737 & 0.0636 \\
& \multicolumn{7}{c}{ Panel B: Comovement in Returns } & & & \\
\hline Group 1 & Variable & Mean & Median & P25 & P75 & Std Dev \\
Full sample & Corr_returns & 0.4459 & 0.4692 & 0.2789 & 0.6348 & 0.2517 \\
Severe downturns & Corr_returns & 0.6321 & 0.6792 & 0.5224 & 0.7845 & 0.2067 \\
Outside of downturns & Corr_returns & 0.4254 & 0.4500 & 0.2639 & 0.6103 & 0.2478 \\
\hline Group 2 & Variable & Mean & Median & P25 & P75 & Std Dev \\
Full sample & Corr_returns & 0.4339 & 0.4607 & 0.2800 & 0.6177 & 0.2524 \\
Severe downturns & Corr_returns & 0.5742 & 0.6113 & 0.4318 & 0.7546 & 0.2293 \\
Outside of downturns & Corr_returns & 0.4187 & 0.4465 & 0.2654 & 0.6014 & 0.2502 \\
\hline
\end{tabular}




\section{Table 2. Margin Trading and Excess Comovement: RDD Analysis}

This table presents results of the analysis of the impact of margin trading eligibility on stock return comovement. The dependent variables is corr_returns, which is defined as the month $t$ correlation of stock is daily returns with the (equal-weighted) average daily market returns. The sample includes all stocks in Groups 1 and 2 with impact costs close to the cutoff of 1\% (based on the CCT bandwidth of $0.16 \%$ ). The explanatory variables are Group 1, a dummy variable equal to 1 if the stock is eligible for margin trading during month $t$, severedownturn, a dummy variable equal to 1 if market returns during month $t$ are in the lowest decile in our sample; and a vector of control variables. The control variables include stock is one-month lagged: standard deviation of stock returns (std_ret), stock returns (mret), rupee volume (logvolume), equity market capitalization (logmcap) and the lagged dependent variable. Std_ret is the standard deviation of daily returns during the month. Mret is the month $t$ stock return, calculated from the closing prices at the ends of months $t-1$ and $t$. Logvolume is the natural log of the daily closing price (in rupees) times the number of shares traded. Logmcap is the equity market capitalization, defined as the end of month $t$ closing price, times shares outstanding. We also include Lag depvar, the one-month lagged dependent variable (corr_returns). Bootstrapped standard errors are in parentheses. ${ }^{* * *}$ denotes significance at the $1 \%$ level; ${ }^{* *}$ denotes significance at the $5 \%$ level; and ${ }^{*}$ denotes significance at the $10 \%$ level.

\begin{tabular}{|c|c|c|c|c|c|}
\hline & $\begin{array}{c}(1) \\
\text { corr_returns }\end{array}$ & $\begin{array}{c}(2) \\
\text { corr_returns }\end{array}$ & $\begin{array}{c}\text { (3) } \\
\text { corr_returns }\end{array}$ & $\begin{array}{c}\text { (4) } \\
\text { corr_returns }\end{array}$ & $\begin{array}{c}\text { (5) } \\
\text { corr_returns }\end{array}$ \\
\hline Group 1 & $\begin{array}{c}0.012^{* *} \\
(0.005)\end{array}$ & $\begin{array}{c}0.007 \\
(0.006)\end{array}$ & $\begin{array}{c}0.009 \\
(0.006)\end{array}$ & $\begin{array}{l}-0.001 \\
(0.006)\end{array}$ & $\begin{array}{c}0.005 \\
(0.006)\end{array}$ \\
\hline Group $1 *$ Severedownturn & & $\begin{array}{c}0.051 * * * \\
(0.017)\end{array}$ & & $\begin{array}{c}0.055^{* * *} \\
(0.019)\end{array}$ & $\begin{array}{c}0.042^{* *} \\
(0.017)\end{array}$ \\
\hline Severedownturn & & $\begin{array}{c}0.155^{* * *} \\
(0.013)\end{array}$ & & $\begin{array}{c}0.130^{* * *} \\
(0.015)\end{array}$ & \\
\hline Lag std_dret & & & $\begin{array}{c}2.032^{* * *} \\
(0.410)\end{array}$ & $\begin{array}{c}2.023 * * * \\
(0.339)\end{array}$ & $\begin{array}{c}2.026^{* * *} \\
(0.385)\end{array}$ \\
\hline Lag mret & & & $\begin{array}{c}-0.090 * * * \\
(0.022)\end{array}$ & $\begin{array}{c}-0.058^{* * *} \\
(0.019)\end{array}$ & $\begin{array}{c}-0.090 \text { *** } \\
(0.022)\end{array}$ \\
\hline Lag logvolume & & & $\begin{array}{c}0.011 * * * \\
(0.004)\end{array}$ & $\begin{array}{c}0.022^{* * *} * \\
(0.003)\end{array}$ & $\begin{array}{c}0.011^{* * * *} \\
(0.004)\end{array}$ \\
\hline Lag logmcap & & & $\begin{array}{c}-0.039 * * * \\
(0.003)\end{array}$ & $\begin{array}{c}-0.036^{* * *} \\
(0.003)\end{array}$ & $\begin{array}{c}-0.039 * * * \\
(0.003)\end{array}$ \\
\hline Lag depvar & & & $\begin{array}{c}0.191 * * * \\
(0.014)\end{array}$ & $\begin{array}{c}0.206^{* * *} \\
(0.014)\end{array}$ & $\begin{array}{c}0.191 * * * \\
(0.014)\end{array}$ \\
\hline Constant & $\begin{array}{c}0.807 * * * \\
(0.018)\end{array}$ & $\begin{array}{c}0.419 * * * \\
(0.004)\end{array}$ & $\begin{array}{c}0.845^{* * *} \\
(0.076)\end{array}$ & $\begin{array}{c}0.741 * * * \\
(0.071)\end{array}$ & $\begin{array}{c}0.845^{* * *} \\
(0.080)\end{array}$ \\
\hline Observations & 7,635 & 7,635 & 5,954 & 5,954 & 5,954 \\
\hline R-squared & 0.230 & 0.049 & 0.300 & 0.147 & 0.301 \\
\hline Month-Year FE & Yes & No & Yes & No & Yes \\
\hline Controls & $\mathrm{No}$ & $\mathrm{No}$ & Yes & Yes & Yes \\
\hline
\end{tabular}




\section{Table 3. RDD Robustness Checks}

This table presents results of the robustness tests for the impact of margin trading eligibility on return comovement. The dependent variables is corr_returns, which is defined as the month $t$ correlation of stock is daily returns with the (equal-weighted) average daily market returns and the explanatory variables are identical to those defined in Table 2. In Panel A, we use "donut hole" regressions to examine the sensitivity of the results to observations that are very close to the cutoff. The sample includes all stocks in Groups 1 and 2 with impact costs close to the cutoff of 1\% (based on the CCT bandwidth of $0.16 \%$ ) except that we remove stocks in the bandwidth of $0.008 \%$ (Column 1) and $0.016 \%$ (Column 2). These correspond to 10\% and 25\% of the CCT bandwidths, respectively. In Panel $\mathrm{B}$, we condition the analysis on the subsample of months in which market returns are in the lowest decile in the full sample. Panel $\mathrm{C}$ shows results of local polynomial regressions in which we expand CCT bandwidths by factors of 1.00 to 1.75 and we add ploynomials of impact cost as well as interactions of impact cost ploynomials with the Group1 dummy. Panel D presents results of the analysis of the relationship between return comovement alternative channels related to index membership, derivatives (and short-selling) eligibility and ownership structure. We add dummy variables for four alternative channels, denoted alt_channel in the table. The definitions for alt_channel are as follows: Index equals 1 if the stock is a member of the CNX 500; Foreign is the percentage foreign ownership; Inst is the percentage institutional ownership; and Deriv is a dummy variable set equal to 1 if futures and options trade on the stock. Short selling is also allowed in the sample of stocks where Deriv equals 1 . Bootstrapped standard errors are in parentheses. ${ }^{* *},{ }^{* *}$, and $*$ denote significance at the $1 \%, 5 \%$, and $10 \%$ levels, respectively.

Panel A. "Donut hole" RDD Regressions

\begin{tabular}{lcc}
\hline & $(1)$ & $(2)$ \\
& "donut hole" $=0.008 \%$ & "donut hole" $=0.016 \%$ \\
\hline Group 1 & -0.001 & -0.000 \\
Group $1 *$ Severedownturn & $(0.006)$ & $(0.007)$ \\
& $0.057^{* * *}$ & $0.058^{* * *}$ \\
Severedownturn & $(0.019)$ & $(0.020)$ \\
& $0.130^{* * *}$ & $0.129^{* * *}$ \\
Lag std_dret & $(0.015)$ & $(0.016)$ \\
& $2.051^{* * *}$ & $1.966^{* * *}$ \\
Lag mret & $(0.316)$ & $(0.359)$ \\
& $-0.060^{* * *}$ & $-0.062^{* * *}$ \\
Lag logvolume & $(0.019)$ & $(0.019)$ \\
& $0.021^{* * *}$ & $0.022^{* * *}$ \\
Lag logmcap & $(0.003)$ & $(0.004)$ \\
& $-0.036^{* * *}$ & $-0.036^{* * *}$ \\
Lag depvar & $(0.003)$ & $(0.003)$ \\
& $0.202^{* * *}$ & $0.208^{* * *}$ \\
Constant & $(0.014)$ & $(0.015)$ \\
& $0.751^{* * *}$ & $0.728^{* * *}$ \\
Observations & $(0.069)$ & $(0.077)$ \\
R-squared & 5,773 & 5,444 \\
\end{tabular}


Panel B. RDD Regressions for the Severe Downturns Subsample

\begin{tabular}{lcc}
\hline & $(1)$ & $(2)$ \\
& corr_returns & corr_returns \\
\hline Group1 & $0.058^{* * *}$ & $0.056^{* * *}$ \\
& $(0.016)$ & $(0.019)$ \\
Lag std_dret & & 0.315 \\
& & $(1.098)$ \\
Lag mret & & $-0.097^{*}$ \\
& & $(0.050)$ \\
Lag logvolume & $0.020^{* *}$ \\
& & $(0.010)$ \\
Lag logmcap & & $-0.039^{* * *}$ \\
& & $(0.010)$ \\
Lag depvar & & $0.171^{* * *}$ \\
& & $(0.043)$ \\
Constant & & $1.025^{* * *}$ \\
& $0.574^{* * *}$ & $(0.209)$ \\
Observations & $(0.013)$ & 535 \\
R-squared & 750 & 0.122 \\
\hline
\end{tabular}


Panel C. RDD Regressions using Impact Cost Polynomials

\begin{tabular}{|c|c|c|c|c|}
\hline & $\begin{array}{c}(1) \\
\text { corr_returns }\end{array}$ & $\begin{array}{c}(2) \\
\text { corr_returns }\end{array}$ & $\begin{array}{c}(3) \\
\text { corr_returns }\end{array}$ & $\begin{array}{c}\text { (4) } \\
\text { corr_returns }\end{array}$ \\
\hline Group1 & $\begin{array}{l}-0.0201 \\
(0.0126)\end{array}$ & $\begin{array}{l}-0.0153 \\
(0.0106)\end{array}$ & $\begin{array}{l}-0.0194 \\
(0.0152)\end{array}$ & $\begin{array}{l}-0.0278 \\
(0.0190)\end{array}$ \\
\hline Group1* Severedownturn & $\begin{array}{c}0.0553 * * * \\
(0.0201)\end{array}$ & $\begin{array}{c}0.0431 * * * \\
(0.0165)\end{array}$ & $\begin{array}{c}0.0370 * * \\
(0.0151)\end{array}$ & $\begin{array}{c}0.0308 * * \\
(0.0149)\end{array}$ \\
\hline Severedownturn & $\begin{array}{c}0.1302^{* * *} \\
(0.0149)\end{array}$ & $\begin{array}{c}0.1386 \text { *** } \\
(0.0130)\end{array}$ & $\begin{array}{c}0.1441 * * * \\
(0.0119)\end{array}$ & $\begin{array}{c}0.1496^{* * *} \\
(0.0120)\end{array}$ \\
\hline Impact Cost & $\begin{array}{c}-0.1695^{*} \\
(0.1029)\end{array}$ & $\begin{array}{l}-0.1089 \\
(0.0756)\end{array}$ & $\begin{array}{l}-0.3349 \\
(0.2418)\end{array}$ & $\begin{array}{l}-0.6745 \\
(0.4744)\end{array}$ \\
\hline Impact Cost * Group1 & $\begin{array}{c}0.1074 \\
(0.1290)\end{array}$ & $\begin{array}{c}0.0534 \\
(0.0976)\end{array}$ & $\begin{array}{c}0.3715 \\
(0.3145)\end{array}$ & $\begin{array}{c}0.6646 \\
(0.5585)\end{array}$ \\
\hline Impact Cost $^{2}$ & & & $\begin{array}{c}1.1766 \\
(0.9737)\end{array}$ & $\begin{array}{c}4.6334 \\
(3.9982)\end{array}$ \\
\hline Impact $\operatorname{Cost}^{2} *$ Group1 & & & $\begin{array}{l}-0.6654 \\
(1.2624)\end{array}$ & $\begin{array}{l}-4.2603 \\
(5.0209)\end{array}$ \\
\hline Impact Cost $^{3}$ & & & & $\begin{array}{l}-9.5645 \\
(9.5418)\end{array}$ \\
\hline Impact $\operatorname{Cost}^{3} *$ Group1 & & & & $\begin{array}{c}10.1138 \\
(11.7493)\end{array}$ \\
\hline Lag std_dret & $\begin{array}{c}2.0555^{* * *} \\
(0.3287)\end{array}$ & $\begin{array}{c}2.2083 * * * \\
(0.2975)\end{array}$ & $\begin{array}{c}2.4728 * * * \\
(0.2803)\end{array}$ & $\begin{array}{c}2.2836^{* * *} * \\
(0.2434)\end{array}$ \\
\hline Lag mret & $\begin{array}{c}-0.0561 * * * \\
(0.0186)\end{array}$ & $\begin{array}{c}-0.0539 * * * \\
(0.0169)\end{array}$ & $\begin{array}{c}-0.0563^{* * *} \\
(0.0158)\end{array}$ & $\begin{array}{c}-0.0547 * * * \\
(0.0142)\end{array}$ \\
\hline Lag logvolume & $\begin{array}{c}0.0214 * * * \\
(0.0036)\end{array}$ & $\begin{array}{c}0.0233 * * * \\
(0.0030)\end{array}$ & $\begin{array}{c}0.0205^{* * *} \\
(0.0028)\end{array}$ & $\begin{array}{c}0.0208^{* * * *} \\
(0.0023)\end{array}$ \\
\hline Lag logmcap & $\begin{array}{c}-0.0366^{* * * *} \\
(0.0032)\end{array}$ & $\begin{array}{c}-0.0361^{* * *} \\
(0.0030)\end{array}$ & $\begin{array}{c}-0.0358^{* * *} \\
(0.0027)\end{array}$ & $\begin{array}{c}-0.0366^{* * *} \\
(0.0025)\end{array}$ \\
\hline Lag depvar & $\begin{array}{c}0.2047 * * * \\
(0.0134)\end{array}$ & $\begin{array}{c}0.2017 * * * \\
(0.0121)\end{array}$ & $\begin{array}{c}0.1976 * * * \\
(0.0118)\end{array}$ & $\begin{array}{c}0.1984 * * * \\
(0.0108)\end{array}$ \\
\hline Constant & $\begin{array}{c}0.7697 * * * \\
(0.0748)\end{array}$ & $\begin{array}{c}0.7229 * * * \\
(0.0666)\end{array}$ & $\begin{array}{c}0.7609 * * * \\
(0.0623)\end{array}$ & $\begin{array}{c}0.7850 * * * \\
(0.0558)\end{array}$ \\
\hline $\begin{array}{l}\text { Observations } \\
\text { R-squared }\end{array}$ & $\begin{array}{l}5,954 \\
0.147\end{array}$ & $\begin{array}{l}7,125 \\
0.152\end{array}$ & $\begin{array}{l}8,681 \\
0.153\end{array}$ & $\begin{array}{c}10,260 \\
0.152\end{array}$ \\
\hline
\end{tabular}


Panel D. Alternative Channels

\begin{tabular}{|c|c|c|c|c|}
\hline & $\begin{array}{c}(1) \\
\text { index }\end{array}$ & $\begin{array}{c}(2) \\
\text { foreign }\end{array}$ & $\begin{array}{l}\text { (3) } \\
\text { inst }\end{array}$ & $\begin{array}{c}\text { (4) } \\
\text { Deriv (or short-selling) }\end{array}$ \\
\hline \multirow[t]{2}{*}{ Group 1} & 0.000 & -0.001 & $-0.020^{* *}$ & -0.002 \\
\hline & $(0.008)$ & $(0.007)$ & $(0.008)$ & $(0.007)$ \\
\hline \multirow[t]{2}{*}{ Group 1* Severedownturn } & $0.042 * *$ & $0.050 * *$ & $0.048^{*}$ & $0.055^{* * *}$ \\
\hline & $(0.020)$ & $(0.021)$ & $(0.028)$ & $(0.020)$ \\
\hline \multirow[t]{2}{*}{ Severedownturn } & $0.135^{* * *}$ & $0.126^{* * *}$ & $0.132 * * *$ & $0.131 * * *$ \\
\hline & $(0.015)$ & $(0.016)$ & $(0.021)$ & $(0.016)$ \\
\hline \multirow[t]{2}{*}{ Group $1 *$ Severedownturn * Alt channel } & 0.081 & 0.040 & 0.049 & -0.063 \\
\hline & $(0.058)$ & $(0.051)$ & $(0.107)$ & $(0.058)$ \\
\hline \multirow[t]{2}{*}{ Group 1* Alt Channel } & -0.009 & -0.008 & $0.097 * * *$ & -0.008 \\
\hline & $(0.018)$ & $(0.017)$ & $(0.034)$ & $(0.054)$ \\
\hline \multirow{2}{*}{ Severedownturn * Alt Channel } & -0.031 & 0.009 & -0.031 & - \\
\hline & $(0.049)$ & $(0.040)$ & $(0.094)$ & \\
\hline \multirow[t]{2}{*}{ Alt Channel } & 0.007 & 0.004 & $-0.073^{* * *}$ & $0.115^{* * *}$ \\
\hline & $(0.014)$ & $(0.013)$ & $(0.027)$ & $(0.042)$ \\
\hline \multirow[t]{2}{*}{ Constant } & $0.748^{* * *}$ & $0.751 * * *$ & $0.741 * * *$ & $0.773 * * *$ \\
\hline & $(0.072)$ & $(0.068)$ & $(0.070)$ & $(0.072)$ \\
\hline Observations & 5,954 & 5,776 & 5,776 & 5,954 \\
\hline R-squared & 0.147 & 0.144 & 0.145 & 0.149 \\
\hline
\end{tabular}




\section{Table 4. Placebo Test for Comovement in Returns}

This table presents results of placebo tests in which we repeat the analyses of the impact of margin trading eligibility on return comovement from Table 2 around false eligibility cutoffs. Instead of measuring eligibility at the true impact cost cutoff of $1.0 \%$, we replicate the analysis around placebo cutoffs set at one bandwidth below and one bandwidth above the actual cutoff. The "Local Sample" used in the analysis consists of those stocks that lie close to the placebo cutoff using the same bandwidth size as in Table $2(0.16 \%)$. The explanatory variables are the Placebo Group 1 dummy and the same vector of control variables defined in Table 2. Bootstrapped standard errors are in parentheses. ${ }^{* * *}$ denotes significance at the 1\% level; ${ }^{* *}$ denotes significance at the $5 \%$ level; and * denotes significance at the $10 \%$ level.

\begin{tabular}{lcc}
\hline & $(1)$ & $(2)$ \\
& Placebo cutoff below & Placebo cutoff above \\
\hline Placebo Group 1 & 0.007 & 0.006 \\
& $(0.006)$ & $(0.008)$ \\
Placebo Group 1 * Severedownturn & -0.007 & -0.014 \\
& $(0.015)$ & $(0.017)$ \\
Severedownturn & $0.151^{* * *}$ & $0.136^{* * *}$ \\
& $(0.011)$ & $(0.012)$ \\
Lag std_dret & $2.450^{* * *}$ & $2.353^{* * *}$ \\
& $(0.290)$ & $(0.354)$ \\
Lag mret & $-0.093^{* * *}$ & $-0.054^{* *}$ \\
& $(0.017)$ & $(0.021)$ \\
Lag logvolume & $0.019^{* * *}$ & $0.022^{* * *}$ \\
& $(0.003)$ & $(0.004)$ \\
Lag logmcap & $-0.038^{* * *}$ & $-0.035^{* * *}$ \\
& $(0.003)$ & $(0.003)$ \\
Lag depvar & $0.198^{* * *}$ & $0.222^{* * *}$ \\
Constant & $(0.012)$ & $(0.015)$ \\
& $0.819^{* * *}$ & $0.695^{* * *}$ \\
Observations & $(0.064)$ & $(0.077)$ \\
R-squared & 7,495 & 4,761 \\
& 0.158 & 0.149 \\
\hline
\end{tabular}


Table 5. Comovement in Returns during Extreme Market Increases

This table presents results of the analyses of the impact of margin trading eligibility on return comovement that is identical to the regressions in Table 2 Columns (2) and (4) except that severedownturn is replaced with Market Rally, a dummy variable that equals 1 in months in which market returns are higher than the $90^{\text {th }}$ percentile of market returns. Bootstrapped standard errors are in parentheses. ${ }^{* * *}$ denotes significance at the $1 \%$ level; ** denotes significance at the $5 \%$ level; and * denotes significance at the $10 \%$ level.

\begin{tabular}{lcc}
\hline & $(1)$ & $(2)$ \\
& corr_returns & corr_returns \\
\hline Group 1 & $0.0125^{* *}$ & 0.0066 \\
Group 1* Market Rally & $(0.0055)$ & $(0.0064)$ \\
& -0.0018 & -0.0160 \\
Market Rally & $(0.0161)$ & $(0.0180)$ \\
& $-0.0781^{* * *}$ & $-0.0679 * * *$ \\
Lag std_dret & $(0.0127)$ & $(0.0140)$ \\
& & $2.4107^{* * *}$ \\
Lag mret & & $(0.3287)$ \\
& & $-0.0555^{* * *}$ \\
Lag logvolume & & $(0.0171)$ \\
& & $0.0199 * * *$ \\
Lag logmcap & & $(0.0034)$ \\
& & $-0.0332^{* * *}$ \\
Lag depvar & & $(0.0031)$ \\
& & $0.2137 * * *$ \\
Constant & & $(0.0137)$ \\
Observations & & $0.7102^{* * *}$ \\
R-squared & $0.4441^{* * *}$ & $(0.0708)$ \\
\hline
\end{tabular}




\section{Table 6. Within Group Pairwise Correlations in Stock Returns}

This table presents results of the analysis of return comovement using pairwise return correlations. For each local stock (stock $\imath$ ), defined as those stocks with impact costs between $0.84 \%$ and $1.16 \%$, we calculate the pairwise correlation of that stock's daily return with daily stock return of all other Group 1 and Group 2 stocks (stock $j$ ). The dependent variable is Corr_return, which is the pairwise correlation in daily stock returns of stock $i$ and stock $j$ in a given month. G1G1 is a dummy variable equal to 1 if both stocks in a given pair are Group 1 stocks; G2G2 is a dummy variable equal to 1 if both stocks in a given pair are Group 2 stocks. The baseline pair consists of one Group 1 and one Group 2 stock. We interact G1G1 and G2G2 with severedownturn, a dummy variable equal to 1 if market returns are below the 10th percentile returns. Columns (1) and (2) present results for the full sample; Column (3) is the same as Column (2) except that we require that both stocks in the pair are in the local sample. In Columns (4) and (5), we use data only from severe downturn periods and we introduce and margin corr, which equals the pairwise correlation in daily margin trading positions for Group1 stocks (this variable equals zero for pairs that include Group 2 stocks) during month $t$. Bootstrapped standard errors are in parentheses. ${ }^{* *}$ denotes significance at the $1 \%$ level; $* *$ denotes significance at the $5 \%$ level; and $*$ denotes significance at the $10 \%$ level.

\begin{tabular}{|c|c|c|c|c|c|}
\hline & $\begin{array}{c}\text { (1) } \\
\text { Stock } i \text { in the local } \\
\text { sample }\end{array}$ & $\begin{array}{c}\text { (2) } \\
\text { Stock } i \text { in the local } \\
\text { sample }\end{array}$ & $\begin{array}{c}\text { (3) } \\
\text { Both stocks in the local } \\
\text { sample }\end{array}$ & $\begin{array}{c}\text { (4) } \\
\text { Stock } i \text { in the local } \\
\text { sample, severe } \\
\text { downturn only }\end{array}$ & $\begin{array}{c}\text { (5) } \\
\text { Both stocks in the local } \\
\text { sample, severe } \\
\text { downturn only }\end{array}$ \\
\hline G1G1 & $\begin{array}{c}0.0245^{* * *} \\
(0.0030)\end{array}$ & $\begin{array}{c}0.0193 * * * \\
(0.0026)\end{array}$ & $\begin{array}{c}0.0028 \\
(0.0026)\end{array}$ & $\begin{array}{c}0.0584 * * * \\
(0.0080)\end{array}$ & $\begin{array}{c}0.0596 * * * \\
(0.0099)\end{array}$ \\
\hline G1G1 * Severedownturn & $\begin{array}{c}0.0262^{* * *} \\
(0.0089)\end{array}$ & $\begin{array}{c}0.0215^{* * *} \\
(0.0077)\end{array}$ & $\begin{array}{c}0.0374^{* * *} \\
(0.0091)\end{array}$ & & \\
\hline Severedownturn & $\begin{array}{c}0.1572^{* * *} \\
(0.0071)\end{array}$ & $\begin{array}{c}0.1619 * * * \\
(0.0066)\end{array}$ & $\begin{array}{c}0.1751 \text { *** } \\
(0.0090)\end{array}$ & & \\
\hline G2G2 & & $\begin{array}{c}-0.0199 * * * \\
(0.0022)\end{array}$ & $\begin{array}{c}-0.0056^{* *} \\
(0.0026)\end{array}$ & $\begin{array}{c}-0.0398 * * * \\
(0.0068)\end{array}$ & $\begin{array}{c}-0.0412^{* * *} \\
(0.0092)\end{array}$ \\
\hline G2G2 * Severedownturn & & $\begin{array}{c}-0.0199 * * * \\
(0.0070)\end{array}$ & $\begin{array}{c}-0.0356 * * * \\
(0.0094)\end{array}$ & & \\
\hline Margin corr & & & & $\begin{array}{c}0.0576^{* * *} \\
(0.0135)\end{array}$ & $\begin{array}{c}0.0403^{* *} \\
(0.0190)\end{array}$ \\
\hline Constant & $\begin{array}{c}0.1802 * * * \\
(0.0028)\end{array}$ & $\begin{array}{c}0.1853^{* * *} \\
(0.0028)\end{array}$ & $\begin{array}{c}0.1942 \text { *** } \\
(0.0034)\end{array}$ & $\begin{array}{c}0.3472 * * * \\
(0.0067)\end{array}$ & $\begin{array}{c}0.3693 * * * \\
(0.0090)\end{array}$ \\
\hline Observations & $6,894,808$ & $6,894,808$ & 584,356 & 628,737 & 53,290 \\
\hline R-squared & 0.037 & 0.038 & 0.043 & 0.010 & 0.010 \\
\hline
\end{tabular}


Table 7. Pairwise Correlations in Stock Returns: Common Trader versus Common Broker Linkages

This table examines the relationship between pairwise return correlations and stocks' connections through margin trading. The dependent variable is the pairwise return correlation during month $t$. Using the trader-level position data, which is available for the 2007 to 2010 subperiod, we construct measures of common margin traders and common brokers. Common traders is the total value of the margin trading positions held by all common traders of the two stocks, scaled by the total market capitalization of the two stocks. Common brokers is the total value of the margin trading positions lent out by all common brokers of the two stocks, scaled by the total market capitalization of the two stocks. Both Common traders and Common brokers are normalized and interacted with severedownturn. Common traders and Common brokers can be defined for margin eligible stocks, and is zero for pairs including Group 2 stocks. Columns (1) to (3) examine common links between local Group 1 stocks (impact costs between $0.84 \%$ and 1\%) and all other G1 and G2 stocks. Column (4) conditions the analysis on stock-pairs where both stocks in the pair are in the local sample (impact costs between $0.84 \%$ and 1.16\%). Bootstrapped standard errors are in parentheses. ${ }^{* *}$ denotes significance at the $1 \%$ level; $* *$ denotes significance at the $5 \%$ level; and $*$ denotes significance at the $10 \%$ level.

\begin{tabular}{|c|c|c|c|c|}
\hline & $\begin{array}{c}\text { (1) } \\
\text { Common Traders }\end{array}$ & $\begin{array}{c}(2) \\
\text { Common Brokers }\end{array}$ & $\begin{array}{c}\text { (3) } \\
\text { Both }\end{array}$ & $\begin{array}{c}\text { (4) } \\
\text { Both, local sample } \\
\text { only }\end{array}$ \\
\hline Common traders $*$ Severedownturn & $\begin{array}{c}0.0117 * * \\
(0.0049)\end{array}$ & & $\begin{array}{c}0.0037 \\
(0.0028)\end{array}$ & $\begin{array}{c}0.0016 \\
(0.0018)\end{array}$ \\
\hline Common traders & $\begin{array}{c}0.0033^{* * *} * \\
(0.0012)\end{array}$ & & $\begin{array}{c}0.0002 \\
(0.0008)\end{array}$ & $\begin{array}{c}0.0003 \\
(0.0014)\end{array}$ \\
\hline Common brokers $*$ Severedownturn & & $\begin{array}{c}0.0271 * * \\
(0.0111)\end{array}$ & $\begin{array}{c}0.0263^{* *} \\
(0.0111)\end{array}$ & $\begin{array}{c}0.0270^{* *} \\
(0.0135)\end{array}$ \\
\hline Common brokers & & $\begin{array}{c}0.0187^{* * *} * \\
(0.0022)\end{array}$ & $\begin{array}{c}0.0188^{* * * *} \\
(0.0022)\end{array}$ & $\begin{array}{c}0.0194 * * * \\
(0.0040)\end{array}$ \\
\hline G1G1 & $\begin{array}{c}0.1837 * * * \\
(0.0085)\end{array}$ & $\begin{array}{c}0.1837 * * * \\
(0.0085)\end{array}$ & $\begin{array}{c}0.1837 * * * \\
(0.0085)\end{array}$ & $\begin{array}{c}0.1931 * * * \\
(0.0125)\end{array}$ \\
\hline G1G1*Severedownturn & $\begin{array}{c}0.0218^{* * *} * \\
(0.0051)\end{array}$ & $\begin{array}{c}0.0211 * * * \\
(0.0051)\end{array}$ & $\begin{array}{c}0.0211^{* * *} \\
(0.0051)\end{array}$ & $\begin{array}{c}0.0131 * * \\
(0.0057)\end{array}$ \\
\hline Severe downturn & $\begin{array}{c}0.0479 * * * \\
(0.0121)\end{array}$ & $\begin{array}{c}0.0408^{* * *} * \\
(0.0120)\end{array}$ & $\begin{array}{c}0.0408^{* * * *} \\
(0.0120)\end{array}$ & $\begin{array}{c}0.0344^{* *} \\
(0.0156)\end{array}$ \\
\hline Constant & $\begin{array}{c}0.2006^{* * *} \\
(0.0037)\end{array}$ & $\begin{array}{c}0.2006^{* * *} \\
(0.0037)\end{array}$ & $\begin{array}{c}0.2006^{* * * *} \\
(0.0037)\end{array}$ & $\begin{array}{c}0.2066^{* * *} * \\
(0.0046)\end{array}$ \\
\hline Observations & $2,843,121$ & $2,843,121$ & $2,843,121$ & 237,772 \\
\hline R-squared & 0.059 & 0.061 & 0.061 & 0.069 \\
\hline
\end{tabular}




\section{Table 8. Margin Trading Regressions with Broker and Trader Portfolio Spillovers}

This table presents results of the regression analysis of daily margin trading activity on broker and trader portfolio returns for the 2007 to 2010 period. The unit of observation is stock and trading day. The dependent variable $c h$ margin is daily change in margin positions in a given stock divided by the stock's previous day-end total margin positions. To calculate trader portfolio returns, we first take the value-weighted average of margin portfolio returns (over all stocks held on margin) of each trader over trading days $t-5$ through $t-1$. We then aggregate to the stock level and we define trader portfolio ret as the value-weighted average of the past 5-day returns of all traders with margin positions in a given stock, where weights are calculated as the trader's investment in the stock, divided by the stock's total outstanding margin positions. To calculate broker portfolio returns, we first take the value-weighted average of trader portfolio returns (over all stocks held on margin) of the clients of a a given broker over trading days $t-5$ through $t-1$, where weights equal the value of each client's total margin positions divided by the total amount lent out by the broker. We then aggregate to the stock level and we define broker portfolio ret as the value-weighted average of past 5-day client portfolio returns of all brokers that provide margin financing in the stock, where weights equal the value of each broker's total margin loan in the stock, divided by the stock's total outstanding margin positions.

In Column (1), we regress the day $t$ change in daily margin positions in stock $i$ on trader portfolio ret. We interact this variable with the severedownturn dummy, which equals 1 if the market return over days $t-5$ through $t-1$ is below the 10th percentile for the period 2007 to 2010 . In Column (2), we regress the day $t$ change in daily margin positions outstanding in stock $i$ on broker portfolio ret and we interact this variable with severedownturn. In Columns (1) and (2), trader and broker margin portfolio returns include returns on stock $i$. In Columns (3) and (4), we repeat the analysis from Columns (1) and (2) refining the definitions of trader portfolio ret and broker portfolio ret. In the new definitions, trader portfolio ret excludes stock $i$; broker portfolio ret excludes all clients holding stock $i$. We also add stock $i$ s return over days $t-5$ through $t-1$ as a separate control variable. In Column (5), we add the overall stock market's 5-day return (Market_ret) as an additional control variable. Column (6) is identical to Columns (5) except that we include stock fixed effects. In Columns (3) to (6), traderportfolio ret is defined as before except that we exclude stock $i$ in the portfolio return calculation; broker portfolio ret is defined as before except that we exclude clients who hold stock $i$.

All standard errors are clustered by ISIN (stock identifier) and trading day. t-statistics are in parentheses.*** denotes significance at the $1 \%$ level; $* *$ denotes significance at the $5 \%$ level; and * denotes significance at the $10 \%$ level. 


\begin{tabular}{|c|c|c|c|c|c|c|}
\hline & $\begin{array}{c}(1) \\
\text { Ch_margin }\end{array}$ & $\begin{array}{c}(2) \\
\text { Ch_margin }\end{array}$ & $\begin{array}{c}(3) \\
C h \_ \text {margin }\end{array}$ & $\begin{array}{c}\text { (4) } \\
\text { Ch_margin }\end{array}$ & $\begin{array}{c}\text { (5) } \\
\text { Ch_margin }\end{array}$ & $\begin{array}{c}(6) \\
C h \_ \text {margin }\end{array}$ \\
\hline Trader portfolio ret & $\begin{array}{c}0.183^{* * *} \\
(0.057)\end{array}$ & $\begin{array}{c}-0.241 * * * \\
(0.080)\end{array}$ & $\begin{array}{c}0.475^{* * *} \\
(0.087)\end{array}$ & $\begin{array}{c}0.060 \\
(0.132)\end{array}$ & $\begin{array}{c}0.032 \\
(0.131)\end{array}$ & $\begin{array}{c}0.060 \\
(0.108)\end{array}$ \\
\hline Trader portfolio ret $*$ Severedownturn & $\begin{array}{c}0.207 \\
(0.181)\end{array}$ & $\begin{array}{c}0.055 \\
(0.153)\end{array}$ & $\begin{array}{c}0.155 \\
(0.250)\end{array}$ & $\begin{array}{l}-0.378 \\
(0.244)\end{array}$ & $\begin{array}{l}-0.388 \\
(0.244)\end{array}$ & $\begin{array}{l}-0.187 \\
(0.238)\end{array}$ \\
\hline Broker portfolio ret & & $\begin{array}{c}0.616^{* * *} \\
(0.104)\end{array}$ & & $\begin{array}{c}0.443^{* * *} \\
(0.121)\end{array}$ & $\begin{array}{l}0.302^{*} \\
(0.182)\end{array}$ & $\begin{array}{c}0.312^{* * *} \\
(0.109)\end{array}$ \\
\hline Broker portfolio ret* Severedownturn & & $\begin{array}{l}0.425^{*} \\
(0.255)\end{array}$ & & $\begin{array}{c}0.733^{* *} \\
(0.312)\end{array}$ & $\begin{array}{c}0.664 * * \\
(0.333)\end{array}$ & $\begin{array}{c}0.500^{* *} \\
(0.208)\end{array}$ \\
\hline Severedownturn & $\begin{array}{c}-0.008 * * \\
(0.003)\end{array}$ & $\begin{array}{c}0.001 \\
(0.004)\end{array}$ & $\begin{array}{c}-0.006^{* *} \\
(0.003)\end{array}$ & $\begin{array}{c}0.001 \\
(0.004)\end{array}$ & $\begin{array}{c}0.001 \\
(0.004)\end{array}$ & $\begin{array}{c}0.003 \\
(0.002)\end{array}$ \\
\hline Stock $i$ ret & & & $\begin{array}{c}-0.093^{* *} \\
(0.042)\end{array}$ & $\begin{array}{c}-0.120^{* * *} \\
(0.042)\end{array}$ & $\begin{array}{c}-0.113^{* * *} \\
(0.042)\end{array}$ & $\begin{array}{c}-0.110^{* * * *} \\
(0.037)\end{array}$ \\
\hline Stock $i$ ret $*$ Severedownturn & & & $\begin{array}{c}0.074 \\
(0.093)\end{array}$ & $\begin{array}{c}0.052 \\
(0.093)\end{array}$ & $\begin{array}{l}-0.004 \\
(0.087)\end{array}$ & $\begin{array}{c}0.012 \\
(0.063)\end{array}$ \\
\hline Market ret & & & & & $\begin{array}{c}0.200 \\
(0.205)\end{array}$ & $\begin{array}{c}0.225^{* *} \\
(0.104)\end{array}$ \\
\hline Market ret $*$ Severedownturn & & & & & $\begin{array}{c}0.121 \\
(0.194)\end{array}$ & $\begin{array}{c}0.082 \\
(0.086)\end{array}$ \\
\hline Constant & $\begin{array}{c}0.017 * * * \\
(0.001)\end{array}$ & $\begin{array}{c}0.016 \text { *** } \\
(0.001)\end{array}$ & $\begin{array}{c}0.016^{* * *} \\
(0.001)\end{array}$ & $\begin{array}{c}0.016^{* * *} \\
(0.001)\end{array}$ & $\begin{array}{c}0.016 \text { *** } \\
(0.001)\end{array}$ & $\begin{array}{c}0.016^{* * *} \\
(0.000)\end{array}$ \\
\hline Observations & 507,854 & 507,854 & 507,854 & 507,854 & 507,854 & 507,854 \\
\hline R-squared & 0.001 & 0.001 & 0.001 & 0.001 & 0.001 & 0.005 \\
\hline Stock FE & No & No & No & No & No & Yes \\
\hline
\end{tabular}




\section{Table 9. Broker and Trader Portfolio Loss Spillovers When Portfolios are Constrained}

This table presents results of the regression analysis of daily margin trading activity on broker and trader portfolio returns for the 2007 to 2010 period. The unit of observation is stock and trading day. The dependent variable ch_margin is daily change in margin positions in a given stock divided by the stock's previous day-end total margin positions. The specifications are similar to those in Column 6 of Table 8 except that we replace the severedownturn interactios with new variables to capture portfolio constraints. Constrained_trader equals trader portfolio ret if trader porffolio ret is less than zero, and zero otherwise. Very_constrained_trader equals trader portfolio ret if trader portfolio ret is less than the 10th percentile trader portfolio ret and zero otherwise. Constrained_broker equals broker portfolio ret if broker portfolio ret is less than zero, and zero otherwise. Very_constrained_broker equals brokerportfolio ret if broker portfolio ret is less than the 10th percentile broke portfolio ret and zero otherwise. The trader and broker portfolio variables exclude $i$, as in Columns (3) through (6) of Table 8. We also add stock $i$ s return and the overall market return over days $t-5$ through $t-1$ as separate control variables (stock_i_ret and market_ret, respectively). All standard errors are clustered by ISIN (stock identifier) and trading day. t-statistics are in parentheses. ${ }^{* * *}$ denotes significance at the $1 \%$ level; ${ }^{* *}$ denotes significance at the $5 \%$ level; and $*$ denotes significance at the $10 \%$ level.

\begin{tabular}{|c|c|c|c|c|}
\hline VARIABLES & $\begin{array}{c}(1) \\
C h \_m a r g i n\end{array}$ & $\begin{array}{c}(2) \\
C h \_m a r g i n\end{array}$ & $\begin{array}{c}\text { (3) } \\
\text { Ch_margin }\end{array}$ & $\begin{array}{c}\text { (4) } \\
\text { Ch_margin }\end{array}$ \\
\hline Trader portfolio ret & $\begin{array}{c}0.041 \\
(0.098)\end{array}$ & $\begin{array}{l}-0.090 \\
(0.111)\end{array}$ & $\begin{array}{c}0.064 \\
(0.148)\end{array}$ & $\begin{array}{c}0.070 \\
(0.149)\end{array}$ \\
\hline Constrained_trader & $\begin{array}{c}0.293^{* * *} \\
(0.100)\end{array}$ & $\begin{array}{c}0.261 * * * \\
(0.099)\end{array}$ & $\begin{array}{l}-0.088 \\
(0.220)\end{array}$ & $\begin{array}{l}-0.067 \\
(0.265)\end{array}$ \\
\hline VeryConstrained_trader & & & & $\begin{array}{c}0.039 \\
(0.131)\end{array}$ \\
\hline Broker portfolio ret & & $\begin{array}{c}0.321 * * * \\
(0.100)\end{array}$ & $\begin{array}{c}0.163 \\
(0.137)\end{array}$ & $\begin{array}{c}0.196 \\
(0.138)\end{array}$ \\
\hline Constrained_broker & & & $\begin{array}{c}0.351^{* *} \\
(0.175)\end{array}$ & $\begin{array}{c}0.122 \\
(0.227)\end{array}$ \\
\hline VeryConstrained_broker & & & & $\begin{array}{c}0.231 * * \\
(0.109)\end{array}$ \\
\hline Stock_i_ret & $\begin{array}{c}-0.093 * * * \\
(0.034)\end{array}$ & $\begin{array}{c}-0.106^{* * *} \\
(0.034)\end{array}$ & $\begin{array}{c}-0.108 * * * \\
(0.034)\end{array}$ & $\begin{array}{c}-0.108^{* * *} \\
(0.034)\end{array}$ \\
\hline Market_ret & $\begin{array}{c}0.536 * * * \\
(0.071)\end{array}$ & $\begin{array}{c}0.341 \text { *** } \\
(0.091)\end{array}$ & $\begin{array}{c}0.333^{* * * *} \\
(0.092)\end{array}$ & $\begin{array}{c}0.328 * * * \\
(0.092)\end{array}$ \\
\hline Constant & $\begin{array}{c}0.016^{* * *} \\
(0.000)\end{array}$ & $\begin{array}{c}0.016^{* * *} \\
(0.000)\end{array}$ & $\begin{array}{c}0.016^{* * *} \\
(0.000)\end{array}$ & $\begin{array}{c}0.016^{* * *} \\
(0.000)\end{array}$ \\
\hline Observations & 508,604 & 507,854 & 507,854 & 507,854 \\
\hline R-squared & 0.005 & 0.005 & 0.005 & 0.005 \\
\hline Stock FE & Yes & Yes & Yes & Yes \\
\hline
\end{tabular}




\section{Table 10. Broker Characteristics and Excess Comovement During Severe Downturns}

This table presents results of regression analysis of daily stock returns on broker characteristics during severe downturs. The sample includes all local Group 1 and Group 2 stocks for the years 2007 to 2010 (the years for which we have broker- and client-level data) and months in which market stock returns are lower than 10th percentile returns. The dependent variable is stock $i$ s day $t$ return. Explanatory variables are: Group1_ret, the equal weighted average day $t$ stock return of all Group 1 stocks, excluding stock $i$; a broker characteristic; and Group1_ret interacted with the broker characteristic. The broker characteristics are Brokersize, Client HHI, ClientPortfHHI, Stock. HHI, BrokerV ol, and Broker Illiq. Each of these variables is standardized. Brokersize is the value weighted average of the size of all brokers whose clients have margin debt in a given stock. The size of each broker is calculated as the rupee value of all outstanding margin positions (across all stocks) of the clients of that broker. Weights equal the total amount lent out by a broker in a given stock, divided by the total outstanding margin debt in that stock. BrokerVol, the month $t-1$ value-weighted average daily volatility of all stocks for which brokers connected to stock $i$ provide margin financing; Brokerlliq, the month $t-1$ value-weighted average Amihud (2002) illiquidity measure of all stocks for which brokers connected to stock $i$ provide margin financing; Client HHI is the day $t$ client Herfindahl-Hirschman Index (HHI), calculated as the sum of the square of each client's share of a broker's outstanding margin loans. ClientPortfHHI is the sum of the squared shares (HHI) of each stock in a brokers' clients' portfolios. The HHI is first calculated for each client, and then ClientPortfHHI is the weighted average of the client HHI, where weights are given by the total value of a client's margin debt divided by all of the broker's margin loans. Stock HHI is sum of the squared shares of all stocks lent out by a broker, where share is defined as the value of margin financing lent out by a broker for stock i, divided by all of the broker's outstanding margin loans. Broker variables are weighted by the value of each broker's (client) holdings in stock $i$. For Group 2 stocks, all broker variables are set to zero. All standard errors are clustered by ISIN (stock identifier) and trading day. tstatistics are in parentheses.*** denotes significance at the $1 \%$ level; $* *$ denotes significance at the $5 \%$ level; and $*$ denotes significance at the $10 \%$ level.

\begin{tabular}{|c|c|c|c|c|c|c|}
\hline & Brokersize & Broker Vol & Broker Illiq & Client_HHI & ClientPortfHHI & Stock $\mathrm{HHI}$ \\
\hline \multirow[t]{2}{*}{ Group1_ret } & $0.9351 * * *$ & $0.9334 * * *$ & $0.9318^{* * *}$ & $0.9320^{* * *}$ & $0.9336^{* * *}$ & $0.9332 * * *$ \\
\hline & $(0.0139)$ & $(0.0135)$ & $(0.0145)$ & $(0.0141)$ & $(0.0138)$ & $(0.0135)$ \\
\hline \multirow[t]{2}{*}{ Group1_ret * Broker Characterisitc } & $0.0388^{* * *}$ & $0.0515^{* * *}$ & $0.0355^{* * *}$ & $0.0338^{* * *}$ & $0.0443 * * *$ & $0.0253 * *$ \\
\hline & $(0.0148)$ & $(0.0124)$ & $(0.0133)$ & $(0.0123)$ & $(0.0134)$ & $(0.0124)$ \\
\hline \multirow[t]{2}{*}{ Broker Characterisitc } & -0.0002 & -0.0002 & -0.0003 & -0.0001 & -0.0002 & -0.0002 \\
\hline & $(0.0004)$ & $(0.0004)$ & $(0.0004)$ & $(0.0004)$ & $(0.0004)$ & $(0.0004)$ \\
\hline \multirow[t]{2}{*}{ Constant } & -0.0004 & -0.0004 & -0.0004 & -0.0004 & -0.0004 & -0.0004 \\
\hline & $(0.0004)$ & $(0.0004)$ & $(0.0004)$ & $(0.0004)$ & $(0.0004)$ & $(0.0004)$ \\
\hline Observations & 8,504 & 8,504 & 8,504 & 8,504 & 8,504 & 8,504 \\
\hline $\mathrm{R}$-squared & 0.415 & 0.416 & 0.415 & 0.415 & 0.415 & 0.415 \\
\hline
\end{tabular}




\section{Internet Appendix to: \\ Margin Trading and Comovement During Crises}

Bige Kahraman and Heather Tookes

IA, page 1 


\section{Figure IA.1: Impact Cost and Covariates}

The figures plot the covariates as a function of impact cost over the previous six months (which determines month $t$ eligibility). The covariates are one-month lagged: standard deviation of stock returns (std_ret), stock returns (mret), rupee volume (logvolume), and equity market capitalization (logmcap). Stocks are divided into ten equally sized bins (the $\mathrm{X}$ axis) on each side of the eligibility cutoff of $1 \%$. The figures show the average value of the the covariate within each bin. The number of bins is chosen based on the F-test procedures described in Lee and Lemieux (2010). Margin eligible stocks are all those stocks with impact costs that are less than or equal to $1 \%$, which are located in bons 1 10 to the left of the vertical line. Stocks in bins 11-20 are ineligible for margin trading during period $t$ and are located to the right of the vertical dotted line. Panel A shows plots outside of severe downturns. Panel B shows plots for severe downturns only (i.e., months in which market returns are below the 10th percentile of the return distribution).

Panel A. Outside Severe Downturns
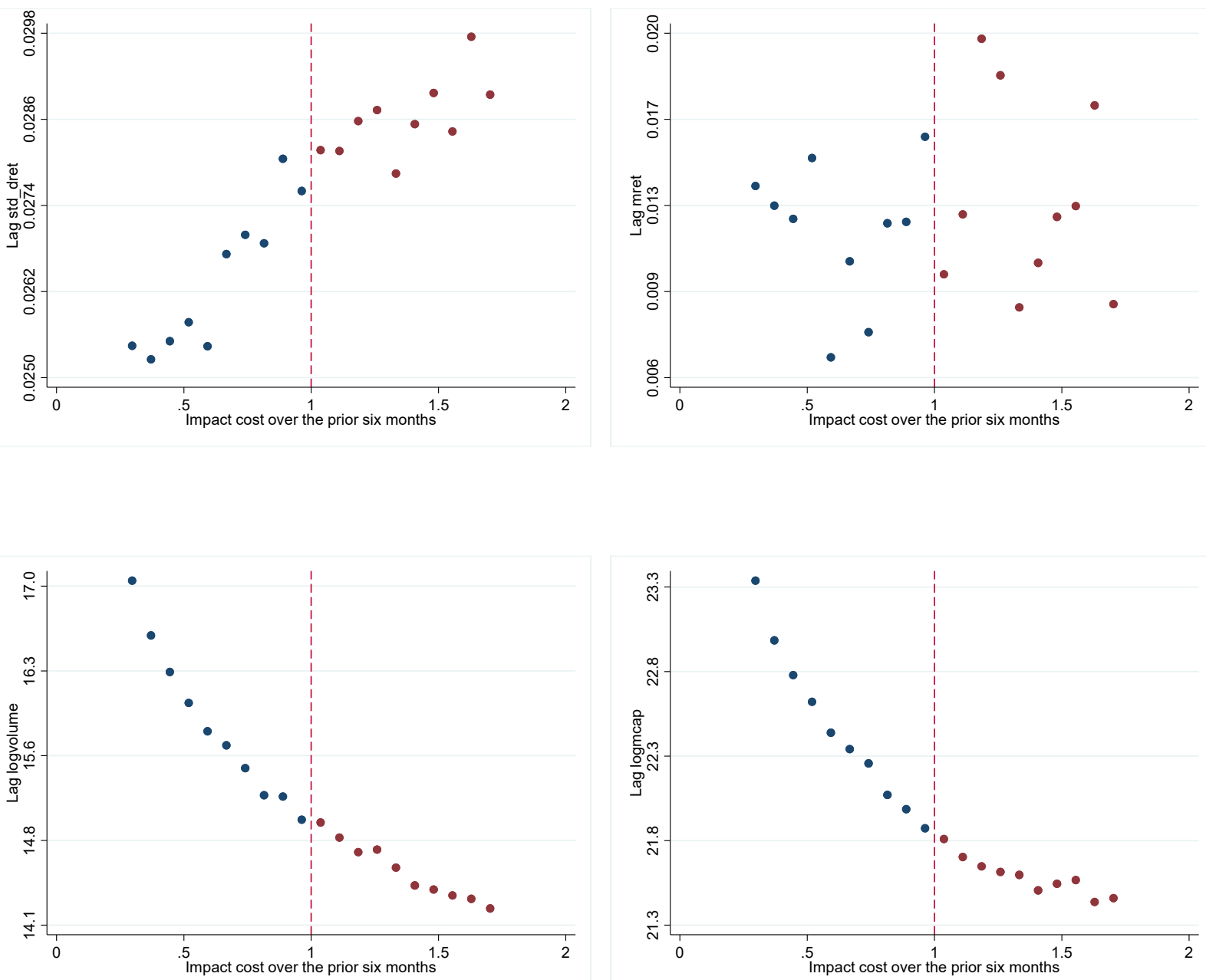

IA, page 2 


\section{Panel B. Severe Downturns}
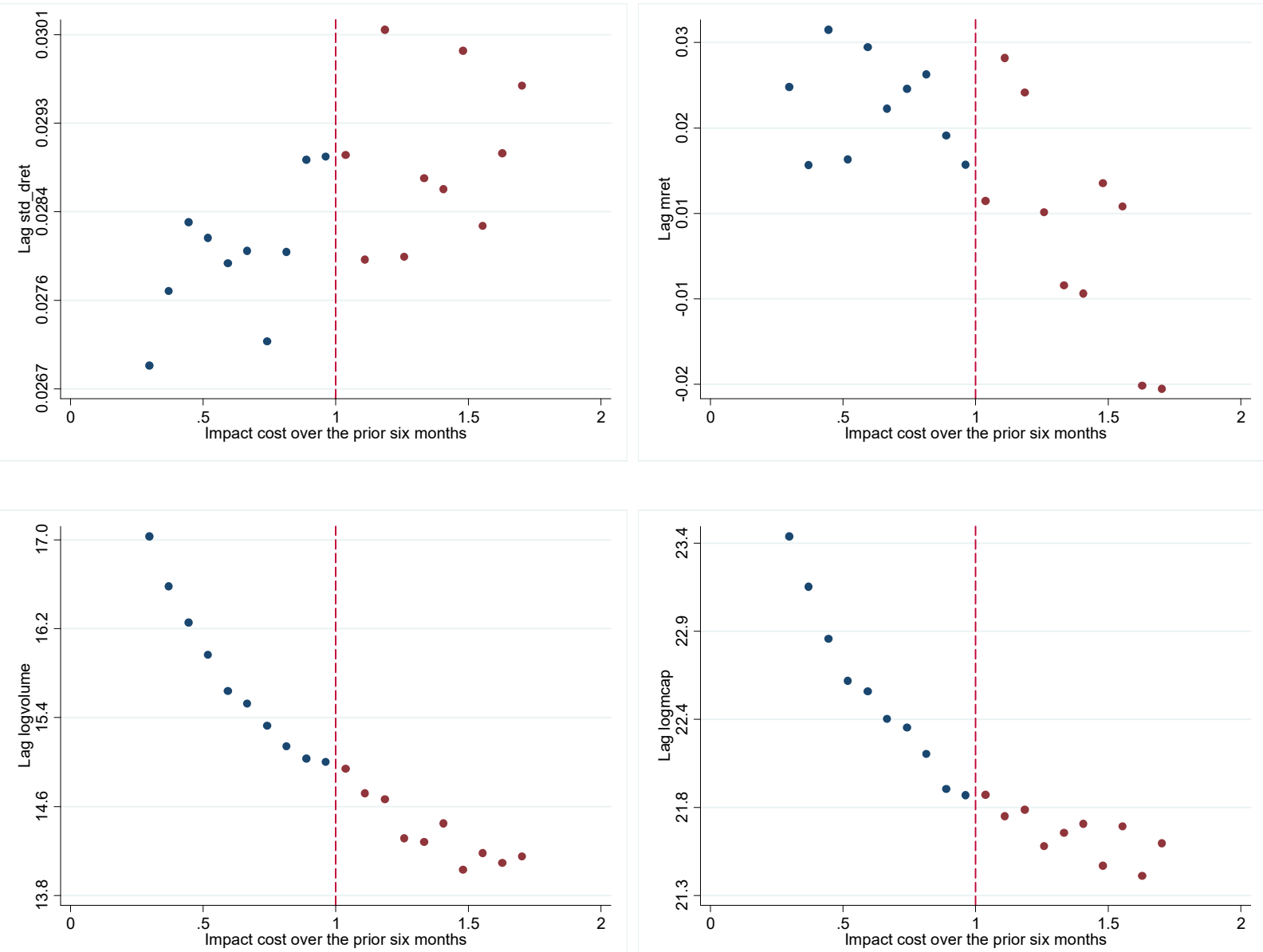

IA, page 3 


\section{Figure IA.2: Impact Cost and The Alternative Comovement Measure}

The figures plot for the alternative comovement measure, $R^{2}$ return, as a function of impact cost over the previous six months (which determines month $t$ eligibility). $R^{2}$ return is defined as the $R^{2}$ from a regression of the daily returns of stock $i$ on equal-weighted daily market returns during month $t$. Stocks are divided into equally sized bins (the $\mathrm{X}$ axis) on each side of the eligibility cutoff of $1 \%$. The figures show the average comovement measure within each bin. The number of bins (10) is chosen based on the F-test procedures described in Lee and Lemieux (2010). Margin eligible stocks are all those stocks with impact costs that are less than or equal to $1 \%$, and are located to the left of the vertical line. "Severe downturns" refers to months in which market returns are below the 10th percentile returns. Panel A shows the range of $0.1 \%$ to $1.9 \%$. Panel B shows the range of $0.25 \%$ to $1.75 \%$ (the interquartile range of impact costs in the data). These plots are identical to those shown in Figure 2, Panels A and B except that we replace corr_returns with $R^{2}$ return.

\section{Panel A}
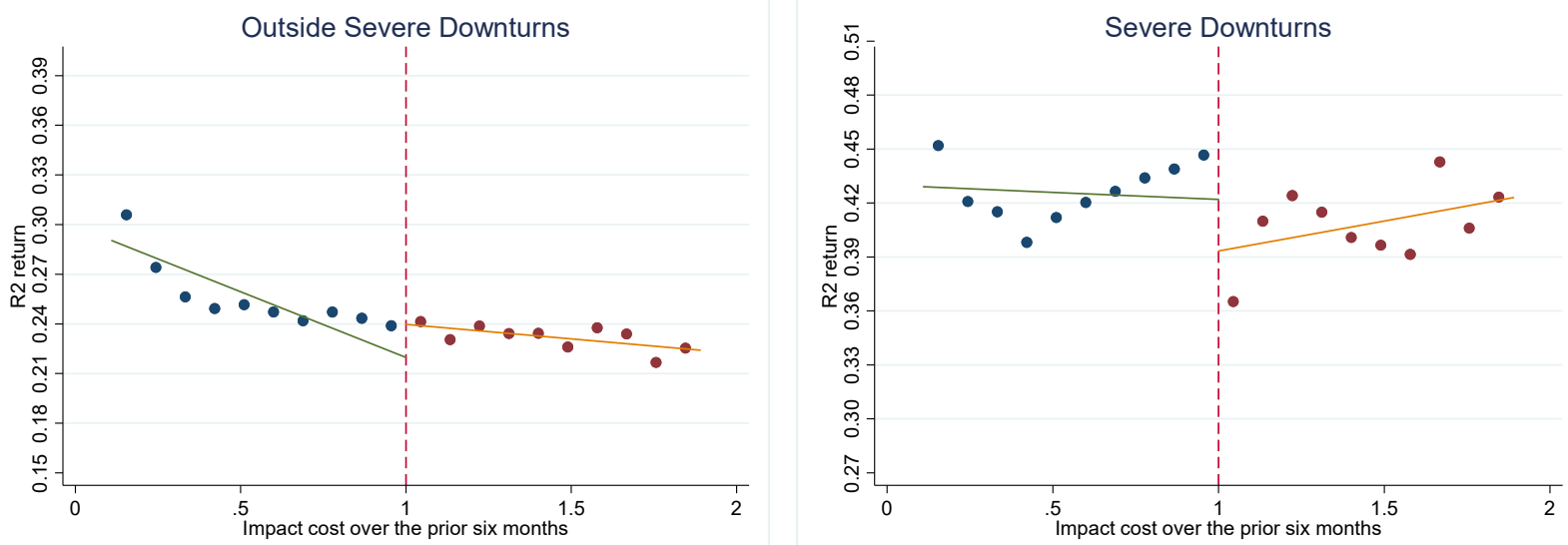

Panel B
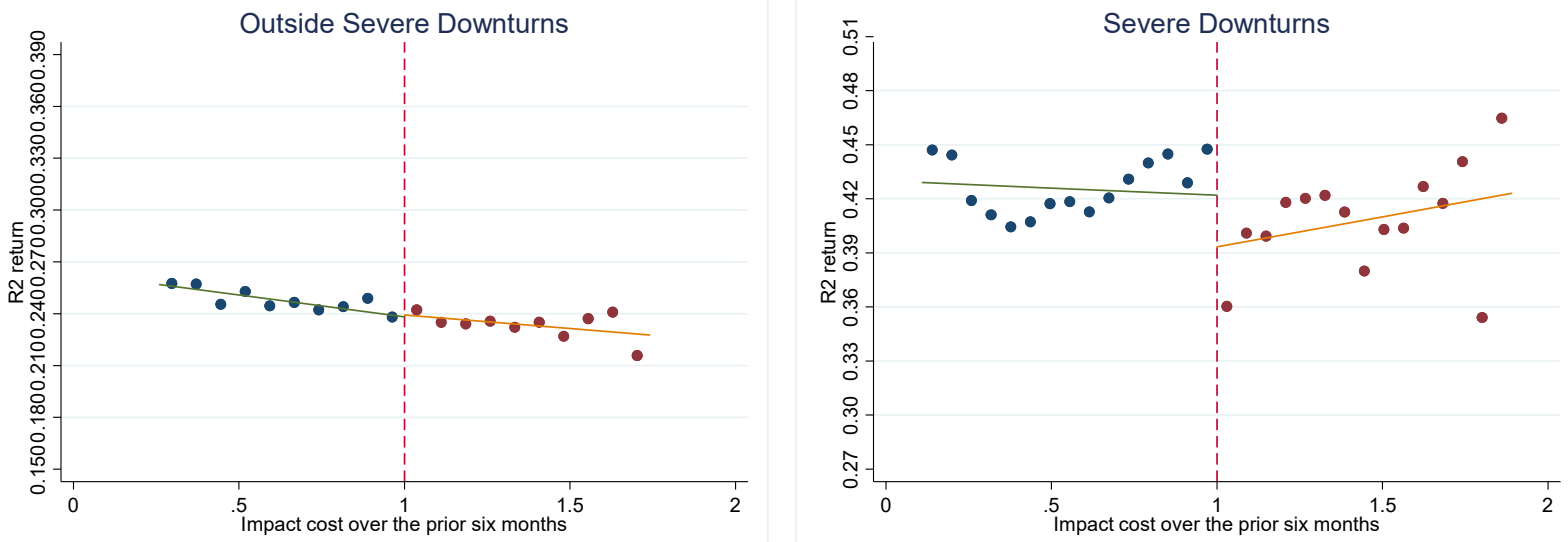

IA, page 4 


\section{Figure IA.3: Impact Cost and Alternative Channels}

The figures plot the alternative channels as a function of impact cost over the previous six months (which determines month $t$ eligibility). The alternative channels are: foreign perc, the percentage foreign ownership; inst perc, the percentage institutional ownership; promoter perc, the percentage promoter/insider ownership (in percent); indiv perc, the percentage ownership of individuals; index, a dummy equal to 1 if the stock is a member of the CNX 500; and F\&O a dummy equal to 1 if the stock is eligible for futures and options (or short-sales) trading. Stocks are divided into ten equally sized bins (the $\mathrm{X}$ axis) on each side of the eligibility cutoff of $1 \%$. The figures show the average value of the the covariate within each bin. The number of bins is chosen based on the F-test procedures described in Lee and Lemieux (2010). Margin eligible stocks are all those stocks with impact costs that are less than or equal to 1\%, which are located in bons 1-10 to the left of the vertical line. Stocks in bins 11-20 are ineligible for margin trading during period $t$ and are located to the right of the vertical dotted line. Panel A shows plots outside of severe downturns. Panel B shows plots for severe downturns only (i.e., months in which market returns are below the 10th percentile of the return distribution).

\section{Panel A. Outside Severe Downturns}
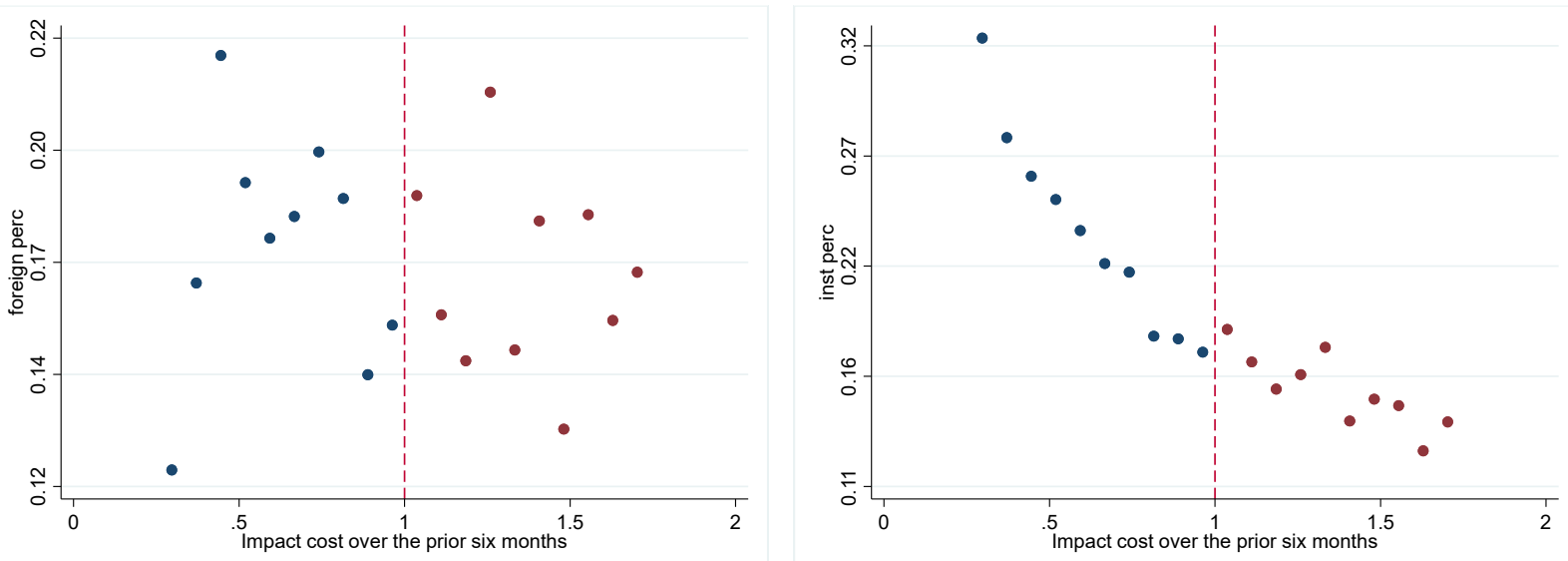

IA, page 5 

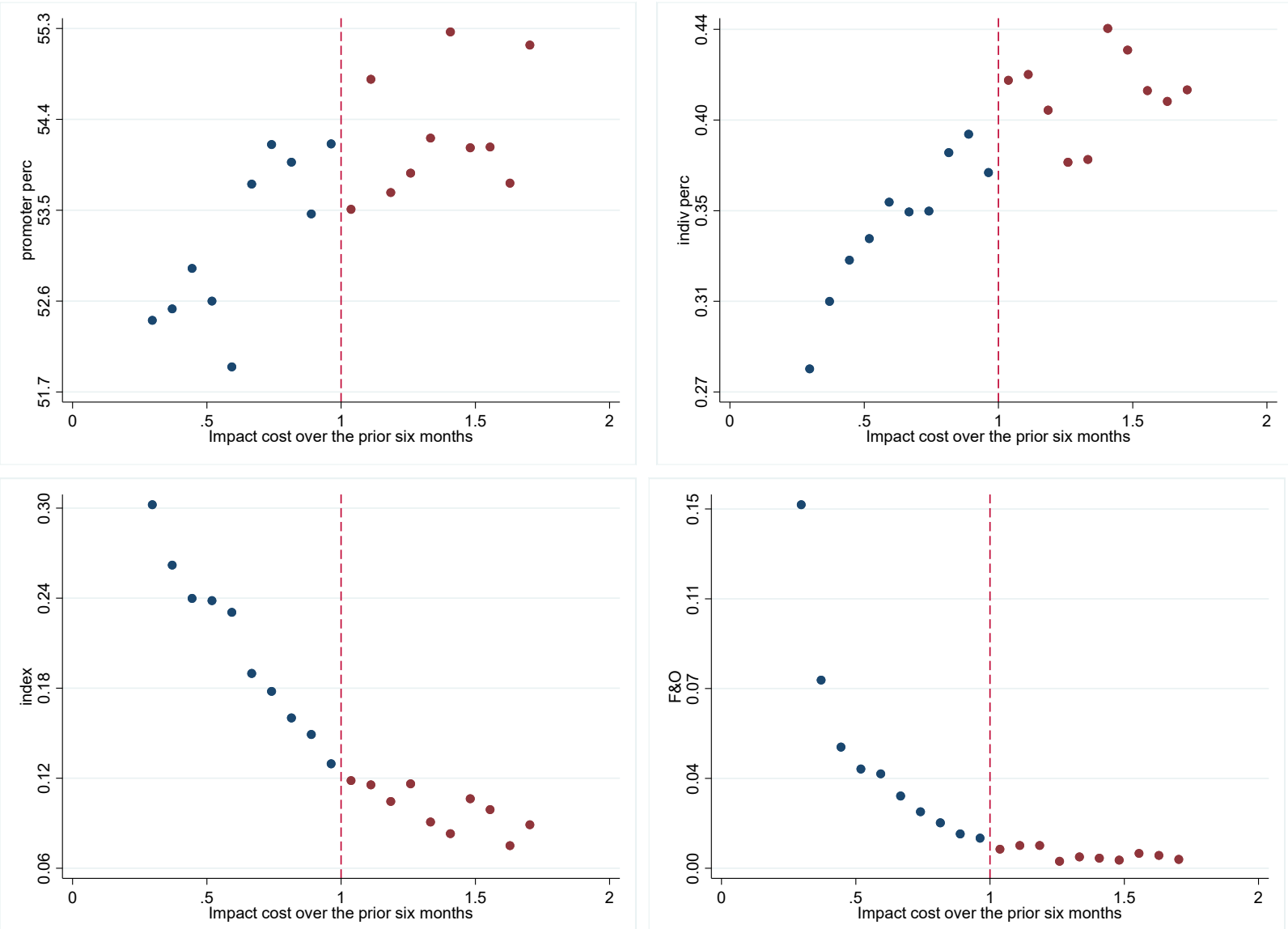

IA, page 6 


\section{Panel B. Severe Downturns}
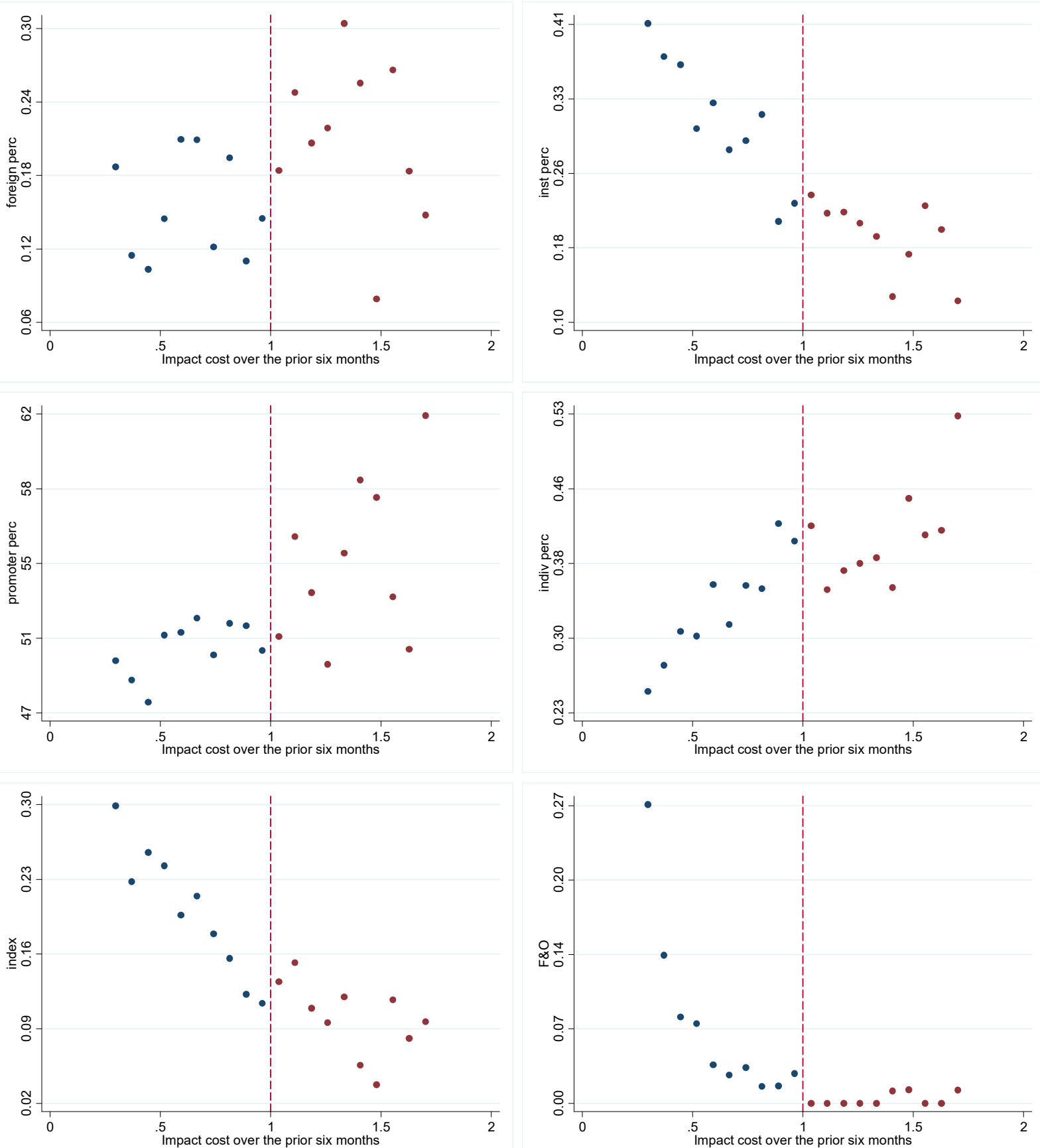

IA, page 7 


\section{Table IA.1. RDD Robustness: Alternative Bandwidths}

This table presents results of the main analysis using alternative bandwidths. The dependent variable is corr_returns, which is defined as the month $t$ correlation of stock $i$ s daily returns with the equalweighted average daily market returns. All variables are defined in Tables 1 and 2. The regression specification is identical to that in Column (4) of Table 2 except that we vary the CCT bandwidth of $0.16 \%$. Columns (1) through (6) increase and decrease the CCT bandwidths in increments of 0.02 . Bootstrapped standard errors are in parentheses. ${ }^{* * *},{ }^{* *}$, and ${ }^{*}$ denote significance at the $1 \%, 5 \%$, and $10 \%$ levels, respectively.

\begin{tabular}{|c|c|c|c|c|c|c|}
\hline & $\begin{array}{c}(1) \\
-0.06 \\
\text { corr_returns }\end{array}$ & $\begin{array}{c}(2) \\
-0.04 \\
\text { corr_returns }\end{array}$ & $\begin{array}{c}(3) \\
-0.02 \\
\text { corr_returns }\end{array}$ & $\begin{array}{c}(4) \\
+0.02 \\
\text { corr_returns }\end{array}$ & $\begin{array}{c}\text { (5) } \\
\quad+0.04 \\
\text { corr_returns }\end{array}$ & $\begin{array}{c}(6) \\
+0.06 \\
\text { corr_returns }\end{array}$ \\
\hline Group 1 & $\begin{array}{l}-0.009 \\
(0.008)\end{array}$ & $\begin{array}{l}-0.006 \\
(0.007)\end{array}$ & $\begin{array}{l}-0.004 \\
(0.007)\end{array}$ & $\begin{array}{l}-0.001 \\
(0.006)\end{array}$ & $\begin{array}{l}-0.001 \\
(0.006)\end{array}$ & $\begin{array}{c}0.002 \\
(0.005)\end{array}$ \\
\hline Group $1 *$ Severedownturn & $\begin{array}{c}0.072^{* * *} \\
(0.025)\end{array}$ & $\begin{array}{c}0.060 * * * \\
(0.021)\end{array}$ & $\begin{array}{c}0.066^{* * * *} \\
(0.021)\end{array}$ & $\begin{array}{c}0.048^{* * *} \\
(0.019)\end{array}$ & $\begin{array}{c}0.047 * * * \\
(0.016)\end{array}$ & $\begin{array}{c}0.041 * * * \\
(0.015)\end{array}$ \\
\hline Severedownturn & $\begin{array}{c}0.120 * * * \\
(0.021)\end{array}$ & $\begin{array}{c}0.129 * * * \\
(0.016)\end{array}$ & $\begin{array}{c}0.128^{* * *} \\
(0.016)\end{array}$ & $\begin{array}{c}0.139 * * * \\
(0.014)\end{array}$ & $\begin{array}{c}0.137 * * * \\
(0.013)\end{array}$ & $\begin{array}{c}0.142^{* * *} \\
(0.012)\end{array}$ \\
\hline Lag std_dret & $\begin{array}{c}2.569 * * * \\
(0.397)\end{array}$ & $\begin{array}{c}2.148^{* * * *} \\
(0.392)\end{array}$ & $\begin{array}{c}1.999 * * * \\
(0.370)\end{array}$ & $\begin{array}{c}2.003^{* * *} \\
(0.305)\end{array}$ & $\begin{array}{c}2.235^{* * *} \\
(0.274)\end{array}$ & $\begin{array}{c}2.393 * * * \\
(0.286)\end{array}$ \\
\hline Lag mret & $\begin{array}{c}-0.059 * * \\
(0.023)\end{array}$ & $\begin{array}{c}-0.050^{* *} \\
(0.022)\end{array}$ & $\begin{array}{c}-0.057^{* * * *} \\
(0.020)\end{array}$ & $\begin{array}{c}-0.050^{* * *} \\
(0.017)\end{array}$ & $\begin{array}{c}-0.059 * * * \\
(0.016)\end{array}$ & $\begin{array}{c}-0.059 * * * \\
(0.017)\end{array}$ \\
\hline Lag logvolume & $\begin{array}{c}0.018^{* * *} \\
(0.004)\end{array}$ & $\begin{array}{c}0.019 * * * \\
(0.004)\end{array}$ & $\begin{array}{c}0.022^{* * *} \\
(0.004)\end{array}$ & $\begin{array}{c}0.023 * * * \\
(0.003)\end{array}$ & $\begin{array}{c}0.023 * * * \\
(0.003)\end{array}$ & $\begin{array}{c}0.022^{* * *} \\
(0.003)\end{array}$ \\
\hline Lag logmcap & $\begin{array}{c}-0.034 * * * \\
(0.004)\end{array}$ & $\begin{array}{c}-0.034 * * * \\
(0.004)\end{array}$ & $\begin{array}{c}-0.036 * * * \\
(0.003)\end{array}$ & $\begin{array}{c}-0.036^{* * * *} \\
(0.003)\end{array}$ & $\begin{array}{c}-0.037 * * * \\
(0.003)\end{array}$ & $\begin{array}{c}-0.037 * * * \\
(0.003)\end{array}$ \\
\hline Lag depvar & $\begin{array}{c}0.198^{* * *} \\
(0.019)\end{array}$ & $\begin{array}{c}0.207 * * * \\
(0.016)\end{array}$ & $\begin{array}{c}0.211 * * * \\
(0.014)\end{array}$ & $\begin{array}{c}0.206 * * * \\
(0.012)\end{array}$ & $\begin{array}{c}0.199 * * * \\
(0.012)\end{array}$ & $\begin{array}{c}0.201 * * * \\
(0.012)\end{array}$ \\
\hline Constant & $\begin{array}{c}0.740 * * * \\
(0.091)\end{array}$ & $\begin{array}{c}0.722^{* * *} \\
(0.077)\end{array}$ & $\begin{array}{c}0.724^{* * *} \\
(0.075)\end{array}$ & $\begin{array}{c}0.713^{* * *} \\
(0.070)\end{array}$ & $\begin{array}{c}0.746^{* * *} \\
(0.069)\end{array}$ & $\begin{array}{c}0.733^{* * *} \\
(0.059)\end{array}$ \\
\hline $\begin{array}{l}\text { Observations } \\
\text { R-squared }\end{array}$ & $\begin{array}{l}3,709 \\
0.151\end{array}$ & $\begin{array}{l}4,455 \\
0.148\end{array}$ & $\begin{array}{l}5,213 \\
0.151\end{array}$ & $\begin{array}{l}6,737 \\
0.149\end{array}$ & $\begin{array}{l}7,537 \\
0.152\end{array}$ & $\begin{array}{l}8,306 \\
0.156\end{array}$ \\
\hline
\end{tabular}




\section{Table IA.2. Alternative Comovement Measure}

Panel A provides summary statistics for the alternative comovement measure, $R^{2}$ return, which is defined as the $R^{2}$ from a regression of the daily returns of stock $i$ on equal-weighted average daily market returns during month $t$. The sample includes all local Group 1 and Group 2 stocks with impact costs close to the eligibility cutoff of $1 \%$ (based on the CCT bandwidth of $0.16 \%$ ). Panel B presents results of the regression analysis of the impact of margin trading eligibility on $R^{2}$ return for the local sample. The explanatory variables and specification are identical to Table 2. Panel $\mathrm{C}$ shows "donut hole" regressions to examine the sensitivity of the results to observations that are very close to the cutoff. The sample includes all stocks in Groups 1 and 2 with impact costs close to the cutoff of 1\% (based on the CCT bandwidth of $0.16 \%$ ) except that we remove stocks in the bandwidth of $0.008 \%$ (Column 1) and $0.016 \%$ (Column 2). Bootstrapped standard errors are in parentheses. *** denotes significance at the $1 \%$ level; $* *$ denotes significance at the $5 \%$ level; and $*$ denotes significance at the $10 \%$ level.

\begin{tabular}{llllllc}
\hline Panel A: Summary Statistics & & & & & & \\
\hline Group 1 & Variable & Mean & Median & P25 & P75 & Std Dev \\
Full sample & $R^{2}$ returns & 0.2622 & 0.2205 & 0.0807 & 0.4030 & 0.2093 \\
Severe downturns & $R^{2}$ returns & 0.4422 & 0.4613 & 0.2729 & 0.6155 & 0.2288 \\
Outside of downturns & $\mathrm{R}^{2}$ returns & 0.2424 & 0.2033 & 0.0726 & 0.3726 & 0.1973 \\
\hline Group 2 & Variable & Mean & Median & P25 & P75 & Std Dev \\
Full sample & $R^{2}$ returns & 0.2519 & 0.2133 & 0.0818 & 0.3819 & 0.2017 \\
Severe downturns & $R^{2}$ returns & 0.3822 & 0.3737 & 0.1865 & 0.5694 & 0.2369 \\
Outside of downturns & $\mathrm{R}^{2}$ returns & 0.2379 & 0.2005 & 0.0758 & 0.3638 & 0.1924 \\
\hline
\end{tabular}

IA, page 9 


\begin{tabular}{|c|c|c|c|c|c|}
\hline \multicolumn{6}{|l|}{ Panel B: RDD Regression } \\
\hline \multirow{3}{*}{ Group1 } & (1) & (2) & (3) & (4) & $(5)$ \\
\hline & $0.010^{* *}$ & 0.004 & $0.008 *$ & -0.002 & 0.004 \\
\hline & $(0.004)$ & $(0.005)$ & $(0.005)$ & $(0.005)$ & $(0.005)$ \\
\hline \multirow[t]{2}{*}{ Group1* Severedownturn } & & $0.056^{* * *}$ & & $0.059 * * *$ & $0.046^{* * *}$ \\
\hline & & $(0.017)$ & & $(0.019)$ & $(0.017)$ \\
\hline \multirow[t]{2}{*}{ Severedownturn } & & $0.144 * * *$ & & $0.118^{* * *}$ & \\
\hline & & $(0.013)$ & & $(0.014)$ & \\
\hline \multirow[t]{2}{*}{ Lag std_dret } & & & $1.535^{* * *}$ & $1.737 * * *$ & $1.528^{* * *}$ \\
\hline & & & $(0.335)$ & $(0.287)$ & $(0.288)$ \\
\hline \multirow[t]{2}{*}{ Lag mret } & & & $-0.064 * * *$ & $-0.045^{* * *}$ & $-0.063 * * *$ \\
\hline & & & $(0.017)$ & $(0.016)$ & $(0.017)$ \\
\hline \multirow[t]{2}{*}{ Lag logvolume } & & & $0.010 * * *$ & $0.018^{* * *}$ & $0.010 * * *$ \\
\hline & & & $(0.003)$ & $(0.003)$ & $(0.003)$ \\
\hline \multirow[t]{2}{*}{ Lag logmcap } & & & $-0.031 * * *$ & $-0.029 * * *$ & $-0.031 * * *$ \\
\hline & & & $(0.003)$ & $(0.003)$ & $(0.002)$ \\
\hline \multirow[t]{2}{*}{ Lag depvar } & & & $0.181^{* * *}$ & $0.190 * * *$ & $0.181 * * *$ \\
\hline & & & $(0.014)$ & $(0.014)$ & $(0.014)$ \\
\hline \multirow[t]{2}{*}{ Constant } & $0.670 * * *$ & $0.238^{* * *}$ & $0.585^{* * *}$ & $0.501^{* * *}$ & $0.584 * * *$ \\
\hline & $(0.022)$ & $(0.004)$ & $(0.059)$ & $(0.057)$ & $(0.055)$ \\
\hline Observations & 7,635 & 7,635 & 5,954 & 5,954 & 5,954 \\
\hline R-squared & 0.283 & 0.067 & 0.343 & 0.157 & 0.344 \\
\hline Month-Year FE & Yes & $\mathrm{No}$ & Yes & No & Yes \\
\hline
\end{tabular}

IA, page 10 
Panel C. "Donut hole" RDD Regressions

\begin{tabular}{lcc}
\hline & $(1)$ & $(2)$ \\
& "donut hole" $=0.008 \%$ & "donut hole" $=0.016 \%$ \\
\hline Group 1 & -0.001 & -0.000 \\
Group 1 * Severedownturn & $(0.006)$ & $(0.007)$ \\
& $0.057^{* * *}$ & $0.058^{* * *}$ \\
Severedownturn & $(0.019)$ & $(0.020)$ \\
& $0.130^{* * *}$ & $0.129^{* * *}$ \\
Lag std_dret & $(0.015)$ & $(0.016)$ \\
& $2.051^{* * *}$ & $1.966^{* * *}$ \\
Lag mret & $(0.316)$ & $(0.359)$ \\
& $-0.060^{* * *}$ & $-0.062^{* * *}$ \\
Lag logvolume & $(0.019)$ & $(0.019)$ \\
& $0.021 * * *$ & $0.022^{* * *}$ \\
Lag logmcap & $(0.003)$ & $(0.004)$ \\
& $-0.036^{* * *}$ & $-0.036^{* * *}$ \\
Lag depvar & $(0.003)$ & $(0.003)$ \\
& $0.202^{* * *}$ & $0.208^{* * *}$ \\
Constant & $(0.014)$ & $(0.015)$ \\
Observations & $0.751^{* * *}$ & $0.728^{* * *}$ \\
R-squared & $(0.069)$ & $(0.077)$ \\
\hline
\end{tabular}

IA, page 11 


\section{Table IA.3. Local Polynomial Regressions for Severe Downturn Periods}

This table presents results of local polynomial regressions in which we use data only for the subsample of severe downturn periods (defined as months in which market returns are in the bottom decile in the sample). The dependent variable is corr_returns, which is defined as the month $t$ correlation of stock is daily returns with the equal-weighted average daily market returns. The regression specification is identical to that in Table 3, Panel $\mathrm{C}$ where we expand CCT bandwidths by factors of 1.00 to 1.75 and we add ploynomials of impact cost as well as interactions of impact cost ploynomials with the Group1 dummy. Bootstrapped standard errors are in parentheses. ***, **, and * denote significance at the $1 \%, 5 \%$, and $10 \%$ levels, respectively.

\begin{tabular}{|c|c|c|c|c|}
\hline & $\begin{array}{c}(1) \\
\text { x1.00 } \\
\text { corr_returns }\end{array}$ & $\begin{array}{c}(2) \\
\text { x1.25 } \\
\text { corr_returns }\end{array}$ & $\begin{array}{c}(3) \\
\text { x1.5 } \\
\text { corr_returns }\end{array}$ & $\begin{array}{c}(4) \\
\text { x1.75 } \\
\text { corr_returns }\end{array}$ \\
\hline Group 1 & $\begin{array}{c}0.0850^{* *} \\
(0.0341)\end{array}$ & $\begin{array}{c}0.0891 * * * \\
(0.0337)\end{array}$ & $\begin{array}{l}0.0740^{*} \\
(0.0419)\end{array}$ & $\begin{array}{l}0.0667 * \\
(0.0347)\end{array}$ \\
\hline Impact Cost & $\begin{array}{c}0.1506 \\
(0.2683)\end{array}$ & $\begin{array}{c}0.2599 \\
(0.2206)\end{array}$ & $\begin{array}{l}-0.1326 \\
(0.7450)\end{array}$ & $\begin{array}{l}-1.1049 \\
(1.5007)\end{array}$ \\
\hline Impact Cost*Group1 & $\begin{array}{c}0.0520 \\
(0.3252)\end{array}$ & $\begin{array}{l}-0.0743 \\
(0.2716)\end{array}$ & $\begin{array}{c}0.3837 \\
(0.9115)\end{array}$ & $\begin{array}{c}0.6654 \\
(1.7478)\end{array}$ \\
\hline Impact $\operatorname{Cost}^{2}$ & & & $\begin{array}{c}1.7775 \\
(3.1662)\end{array}$ & $\begin{array}{c}11.5192 \\
(12.3448)\end{array}$ \\
\hline Impact $\operatorname{Cost}^{2} *$ Group1 & & & $\begin{array}{l}-0.9604 \\
(3.7577)\end{array}$ & $\begin{array}{l}-17.1161 \\
(14.7031)\end{array}$ \\
\hline Impact $\operatorname{Cost}^{3}$ & & & & $\begin{array}{l}-26.4916 \\
(28.8172)\end{array}$ \\
\hline Impact Cost $^{3 *}$ Group1 & & & & $\begin{array}{c}10.9066 \\
(34.1139)\end{array}$ \\
\hline Lag std_dret & $\begin{array}{c}0.2516 \\
(1.0866)\end{array}$ & $\begin{array}{c}0.6549 \\
(1.0705)\end{array}$ & $\begin{array}{c}1.3975 \\
(0.9353)\end{array}$ & $\begin{array}{l}1.6979 * \\
(0.9160)\end{array}$ \\
\hline Lag mret & $\begin{array}{c}-0.0987 * * \\
(0.0456)\end{array}$ & $\begin{array}{c}-0.1020^{* *} \\
(0.0433)\end{array}$ & $\begin{array}{c}-0.0895^{* *} \\
(0.0421)\end{array}$ & $\begin{array}{c}-0.0755^{* *} \\
(0.0372)\end{array}$ \\
\hline Lag logvolume & $\begin{array}{c}0.0210^{* *} \\
(0.0098)\end{array}$ & $\begin{array}{c}0.0252^{* * *} \\
(0.0088)\end{array}$ & $\begin{array}{c}0.0222 * * * \\
(0.0077)\end{array}$ & $\begin{array}{c}0.0216^{* * *} \\
(0.0079)\end{array}$ \\
\hline Lag logmcap & $\begin{array}{c}-0.0386 * * * \\
(0.0103)\end{array}$ & $\begin{array}{c}-0.0387 * * * \\
(0.0096)\end{array}$ & $\begin{array}{c}-0.0386^{* * *} * \\
(0.0080)\end{array}$ & $\begin{array}{c}-0.0358^{* * *} \\
(0.0076)\end{array}$ \\
\hline Lag depvar & $\begin{array}{c}0.1718^{* * *} \\
(0.0437)\end{array}$ & $\begin{array}{c}0.1857 * * * \\
(0.0372)\end{array}$ & $\begin{array}{c}0.1558^{* * *} \\
(0.0345)\end{array}$ & $\begin{array}{c}0.1782^{* * *} \\
(0.0304)\end{array}$ \\
\hline Constant & $\begin{array}{c}0.9918^{* * *} \\
(0.2219)\end{array}$ & $\begin{array}{c}0.9054 * * * \\
(0.2030)\end{array}$ & $\begin{array}{c}0.9552 * * * \\
(0.1717)\end{array}$ & $\begin{array}{c}0.9062^{* * *} \\
(0.1608)\end{array}$ \\
\hline $\begin{array}{l}\text { Observations } \\
\text { R-squared }\end{array}$ & $\begin{array}{c}535 \\
0.124\end{array}$ & $\begin{array}{c}664 \\
0.136\end{array}$ & $\begin{array}{c}826 \\
0.122\end{array}$ & $\begin{array}{c}967 \\
0.131\end{array}$ \\
\hline
\end{tabular}

IA, page 12 
Table IA.4. Within-Group Pairwise Correlations in Stock Returns (2007-2010 subsample)

This table presents results of the analysis of return comovement using pairwise correlations. The regressions are identical to those in Table 6 except we only include data from the 2007-2010 subsample. For each local stock (stock $\imath$ ), defined as those stocks with impact costs between $0.84 \%$ and $1.16 \%$, we calculate the pairwise correlation of the stock's daily return with daily stock return of all other Group 1 and Group 2 stocks (stock $j$ ). The dependent variable is Corr_return, which is the pairwise correlation in daily stock returns of stock $i$ and stock $j$ in a given month. G1G1 is a dummy variable equal to 1 if both stocks in a given pair are Group 1 stocks; G2G2 is a dummy variable equal to 1 if both stocks in a given pair are Group 2 stocks. The baseline pair is a pair that consists of one Group 1 and one Group 2 stock. We interact G1G1 and G2G2 with severedownturn, a dummy variable equal to 1 if market returns are below the 10th percentile returns. Columns (1) and (2) present results for the full sample; Column (3) is the same as Column (2) except that we require that both stocks in the pair are in the local sample. In Columns (4) and (5), we use data only from severe downturn periods and we introduce and margin corr, which equals the pairwise correlation in daily margin trading positions for Group1 stocks (this variable equals zero for pairs that include Group 2 stocks) during month t. Bootstrapped standard errors are in parentheses. *** denotes significance at the $1 \%$ level; ** denotes significance at the $5 \%$ level; and $*$ denotes significance at the $10 \%$ level.

\begin{tabular}{|c|c|c|c|c|c|}
\hline & $\begin{array}{c}\text { (1) } \\
\text { Stock } i \text { in the local } \\
\text { sample }\end{array}$ & $\begin{array}{c}\text { (2) } \\
\text { Stock } i \text { in the local } \\
\text { sample }\end{array}$ & $\begin{array}{c}\text { (3) } \\
\text { Both stocks in the } \\
\text { local sample }\end{array}$ & $\begin{array}{c}\text { (4) } \\
\text { Stock } i \text { in the local } \\
\text { sample }\end{array}$ & $\begin{array}{c}\text { (5) } \\
\text { Both stocks in the } \\
\text { local sample }\end{array}$ \\
\hline G1G1 & $\begin{array}{c}0.0173 * * * \\
(0.0045)\end{array}$ & $\begin{array}{c}0.0135^{* * *} \\
(0.0041)\end{array}$ & $\begin{array}{c}0.0049 \\
(0.0039)\end{array}$ & $\begin{array}{c}0.0534 * * * \\
(0.0094)\end{array}$ & $\begin{array}{c}0.0460 * * * \\
(0.0113)\end{array}$ \\
\hline G1G1 * Severedownturn & $\begin{array}{c}0.0418^{* * *} * \\
(0.0109)\end{array}$ & $\begin{array}{c}0.0329 * * * \\
(0.0092)\end{array}$ & $\begin{array}{c}0.0313^{* * *} * \\
(0.0114)\end{array}$ & & \\
\hline Severedownturn & $\begin{array}{c}0.1837 * * * \\
(0.0085)\end{array}$ & $\begin{array}{c}0.1925^{* * * *} \\
(0.0080)\end{array}$ & $\begin{array}{c}0.2017 * * * \\
(0.0113)\end{array}$ & & \\
\hline G2G2 & & $\begin{array}{c}-0.0145^{* * * *} \\
(0.0032)\end{array}$ & $\begin{array}{c}-0.0084^{* *} * \\
(0.0039)\end{array}$ & $\begin{array}{c}-0.0484 * * * \\
(0.0086)\end{array}$ & $\begin{array}{c}-0.0437 * * * \\
(0.0129)\end{array}$ \\
\hline G2G2 * Severedownturn & & $\begin{array}{c}-0.0340^{* * *} \\
(0.0087)\end{array}$ & $\begin{array}{c}-0.0353 * * * \\
(0.0131)\end{array}$ & & \\
\hline Margin Corr & & & & $\begin{array}{c}0.0094^{*} \\
(0.0052)\end{array}$ & $\begin{array}{l}0.0086^{*} \\
(0.0048)\end{array}$ \\
\hline Constant & $\begin{array}{c}0.2006^{* * *} \\
(0.0037)\end{array}$ & $\begin{array}{c}0.2045^{* * *} \\
(0.0036)\end{array}$ & $\begin{array}{c}0.2090^{* * *} \\
(0.0044)\end{array}$ & $\begin{array}{c}0.3970^{* * *} \\
(0.0079)\end{array}$ & $\begin{array}{c}0.4108^{* * *} \\
(0.0113)\end{array}$ \\
\hline Observations & $3,207,456$ & $3,207,456$ & 266,170 & 371,334 & 33,146 \\
\hline R-squared & 0.060 & 0.061 & 0.071 & 0.020 & 0.016 \\
\hline
\end{tabular}

IA, page 13 


\section{Appendix Table A.5. Ownership Structure}

This table presents results of the analysis of the impact of margin trading eligibility on the ownership structure and the probability of informed trading in NSE stocks. The sample includes all stocks in Groups 1 and 2 with impact costs close to the cutoff of 1\% (based on CCT bandwidths). For each stock, we calculate the percentage shares held by foreign investors, institutional investors, individual investors, and blockholders/insiders (foreign perc, inst perc, indiv_perc, and promoter_perc, respectively). We then regress these dependent variables on the Group 1 dummy as well as its interaction with severedownturn. The other explanatory variables are defined in Table 3 of the main text. Bootstrapped standard errors are in parentheses. ${ }^{* * *}$ denotes significance at the $1 \%$ level; ${ }^{* *}$ denotes significance at the $5 \%$ level; and $*$ denotes significance at the $10 \%$ level.

\begin{tabular}{lcccc}
\hline \multirow{2}{*}{ VARIABLES } & $(1)$ & $(2)$ & $(3)$ & $(4)$ \\
Group1 & foreign_perc & inst_perc & indiv_perc & promoter_perc \\
\hline Group1 * Severedownturn & -0.007 & -0.005 & -0.010 & -0.002 \\
& $(0.015)$ & $(0.007)$ & $(0.009)$ & $(0.002)$ \\
Severedownturn & -0.048 & 0.026 & 0.032 & -0.004 \\
& $(0.049)$ & $(0.021)$ & $(0.023)$ & $(0.006)$ \\
Lag std dret & 0.008 & 0.021 & 0.004 & $-0.010^{* *}$ \\
& $(0.038)$ & $(0.015)$ & $(0.019)$ & $(0.004)$ \\
Lag mret & 0.616 & 0.232 & -0.650 & 0.054 \\
& $(0.705)$ & $(0.375)$ & $(0.444)$ & $(0.094)$ \\
Lag logvolume & $0.113^{* * *}$ & -0.022 & $-0.081 * * *$ & $0.016^{* * *}$ \\
& $(0.038)$ & $(0.019)$ & $(0.026)$ & $(0.005)$ \\
Lag logmcap & $-0.060^{* * *}$ & 0.000 & $0.019^{* * *}$ & $-0.009^{* * *}$ \\
& $(0.008)$ & $(0.003)$ & $(0.005)$ & $(0.001)$ \\
Constant & $0.113^{* * *}$ & $0.061^{* * *}$ & $-0.093^{* * *}$ & $0.019^{* * *}$ \\
& $(0.009)$ & $(0.004)$ & $(0.004)$ & $(0.001)$ \\
& $-1.412^{* * *}$ & $-1.154^{* * *}$ & $2.175^{* * *}$ & $-0.122^{* * *}$ \\
Observations & $(0.173)$ & $(0.072)$ & $(0.104)$ & $(0.022)$ \\
R-squared & & & & \\
\hline
\end{tabular}

IA, page 14 